\title{
Comparison of Engine Simulation Software for Development of Control System
}

\author{
KinYip Chan, Andrzej Ordys, Konstantin Volkov, and Olga Duran \\ School of Mechanical and Automotive Engineering, Faculty of Science, Engineering and Computing, Kingston University, Friars Avenue, \\ Roehampton, London SW15 3DW, UK
}

Correspondence should be addressed to KinYip Chan; k0963725@kingston.ac.uk

Received 14 March 2013; Accepted 29 May 2013

Academic Editor: Luis Carlos Rabelo

Copyright (C) 2013 KinYip Chan et al. This is an open access article distributed under the Creative Commons Attribution License, which permits unrestricted use, distribution, and reproduction in any medium, provided the original work is properly cited.

\begin{abstract}
Most commonly used commercial engine simulation packages generate detailed estimation of the combustion and gas flow parameters. These parameters are required for advanced research on fluid flow and heat transfer and development of geometries of engine components. However, engine control involves different operating parameters. Various sensors are installed into the engine, the combustion performance is recorded, and data is sent to engine control unit (ECU). ECU computes the new set of parameters to make fine adjustments to actuators providing better engine performance. Such techniques include variable valve timing, variable ignition timing, variable air to fuel ratio, and variable compression ratio. In the present study, two of the commercial packages, Ricardo Wave and Lotus Engine Simulation, have been tested on the capabilities for engine control purposes. These packages are compared with an in-house developed package and with reference results available from the literature. Different numerical experiments have been carried out from which it can be concluded that all packages predict similar profiles of pressure and temperature in the engine cylinder. Moreover, those are in reasonable agreement with the reference results while in-house developed package is possible to run simulations with changing speed for engine control purpose.
\end{abstract}

\section{Introduction}

Lately, control engineers in the automotive industry have been challenged with the task of improving fuel consumption and engine performance while simultaneously reducing pollutant emissions. Engines fitted with electronic control provide flexibility to adjust the engine parameters to achieve certain performance. However, it has to be noted that those requirements can lead to contradictory constrains to be satisfied by the control algorithms.

The main component of the electronic control system is the engine control unit (ECU), an electronic device which is connected to the engine sensors and actuators to calculate the best parameters needed to perform efficient combustion, and hence provide cleaner exhaust gas and better engine performance [1].

Sensors connected to ECU in Figure 1 may be used in open loop strategies, such as air-flow sensor, air temperature sensor, and throttle position sensor. In open loop configuration, the ECU adjusts the engine parameters according to the sensors outputs with the help of look-up tables. Other types of sensors, such as lambda sensor, engine temperature sensor, or knock sensor are used on closed loop control configuration. The engine parameters, such as the ignition timing, are then continuously updated according to the feedback of the particular sensor.

In order to develop suitable controls strategies, simulation has been a valuable tool to predict and optimise key parameters in the engine control system. It allows flexible and low cost development of control algorithms without the need of engine bed. Once the algorithm has been developed and tested, it may be installed into the ECU.

Various commercial packages have been developed and are available to solve engineering problems related to design and optimisation of internal combustion engines (ICEs). There are four primary engine simulation commercial packages used in the automotive industry today: Ricardo Wave (RW), Lotus Engine Simulation (LESoft), AVL fire, and GTPower. These packages are similar in purpose and functionality. They require detailed input parameters to simulate 


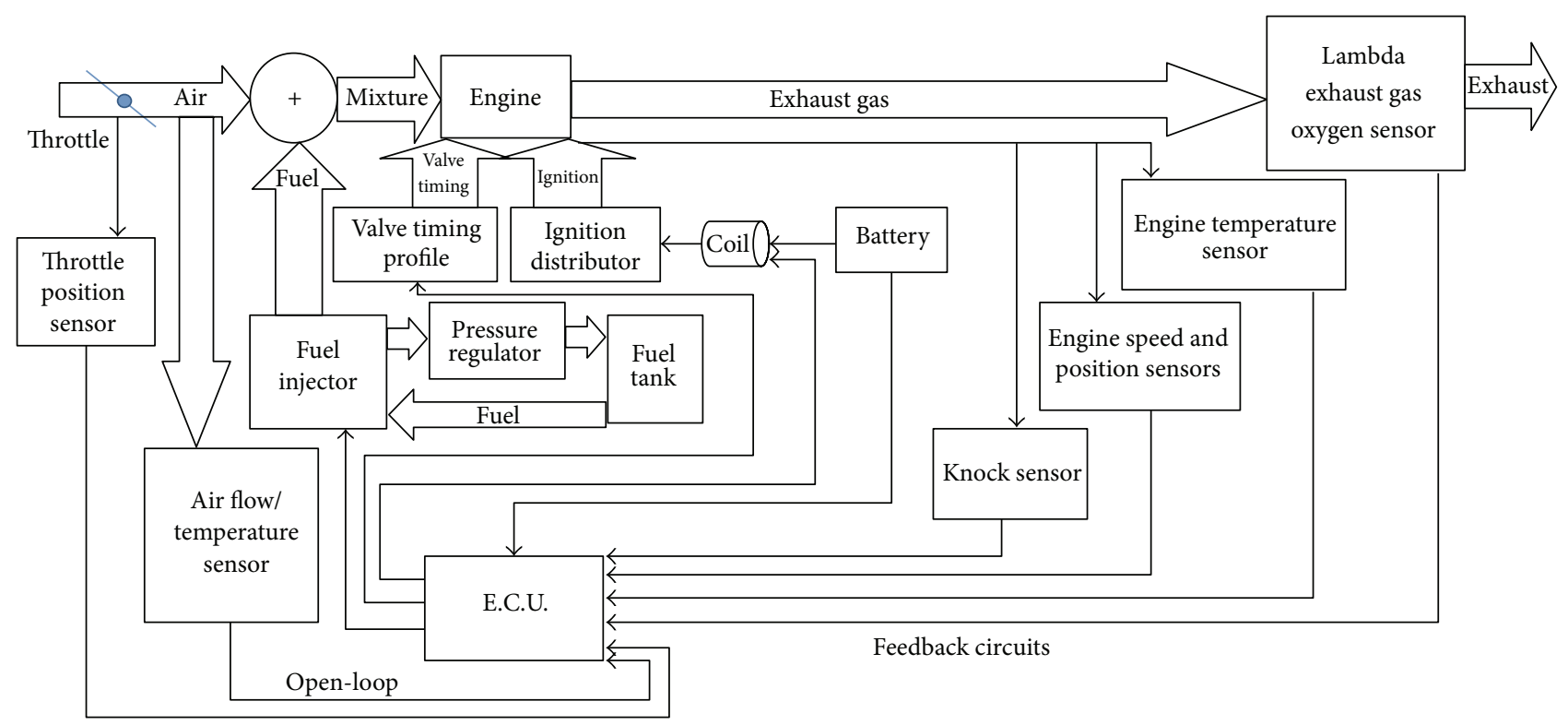

FIGURE 1: Block diagram of engine control system.

the engine operation in an integrated manner rather than using different subsystems.

LESoft is an in-house code developed by Lotus Engineering. The package processes engine simulation in two modules, the data module and the solver module [2]. The data module allows user to input the engine dimension data. The solver module is a built in combustion and heat transfer zero-dimensional equations and fuel/gas composition solver according to user input data in data module. The code is able to predict gas flow, combustion and overall performance of ICEs.

RW is an engine simulation package designed to analyze the dynamics of pressure waves, mass flows, energy losses in ducts, plenums, and manifolds of various systems and machines [3]. RW provides simulation of time-dependent fluid dynamics and thermodynamics using two-zone model.

However, software costs generally prohibit use in small organizations, primarily making them industry-specific software packages. Moreover, commercial software packages are based on computation fluid dynamics (CFD) since they are designed to improve mechanical aspects of the engine. While mechanical models are used to calculate the moving parts of the engine in order to obtain the engine torque and acceleration, control models are used to allow calculations in feedback control schemes to optimise engine performance, such as variable valve timing, ignition timing, air to fuel ratio, and other variable engine geometries systems. Open source packages have been developed by small research groups to solve specific issues.

The in-house package, Matlab Engine Simulation Code (MESC), has been developed in the Kingston University for solution of optimisation problems related to development and operation of ICEs. The code solves a full engine cycle with compression, combustion, expansion, exhaust, and intake strokes in a single cylinder model. User is able to specify cylinder geometry and input data such as air and fuel composition, valve and ignition timing, engine speed, parameters for heat transfer, and heat release submodels. The solver is based on two-zone model and uses the first law of thermodynamics and real-gas law to calculate pressure, temperature, heat flux, and other functions. On top compared to commercial software packages, the code gives more flexibility on engine control using various fuel compositions.

The purpose of this study is to investigate the capabilities of commercial engine simulation packages and in-house Matlab code for control optimisation problems. The flexibility of the different packages is investigated, and the accuracy of ICE models is compared.

The paper is organised as follows. The main parameters needed for engine control are described in Section 2. The submodels behind the simulation packages are described in Section 3. Comparison of different packages under particular conditions and software simulation results are presented in Section 4. Finally, conclusions are drawn in Section 5.

\section{Variables for Engine Control}

During the compression stroke in the engine, the mixture rises to high temperature and maximum pressure. ECU controls the pressure and temperature thought the amount of air intake, the amount of fuel injection, the amount of exhaust gas recirculation, the injection timing, and the ignition timing if applied. There are some researches dedicated to modifications of cylinder geometries by the aid of mechanical parts to vary the compression ratio when needed $[4,5]$. This section explains the current advances in this area.

2.1. Operating Parameters. Performance of ICEs depends on several geometric and thermodynamic parameters. The volume of the combustion chamber is calculated from 
the dimension of the cylinder. The cylinder is assumed to be a fixed bore size and a stroke length. When the piston is moving, volume is calculated according to crank-slider model which depends on the connecting rod length as a function of crank angle. The piston movement is also a factor to estimate heat transfer, blow-by losses, and energy losses due to friction. The combustion performance is treated using thermodynamic calculations with heat release submodels.

\subsection{Avoid Autoignition and Engine Knocking. Autoignition} happens when the mixture reaches autoignition temperature and ignites in the different part of combustion chamber while spark plug ignites, causing more than one frame envelope generate in the combustion chamber. Resultant the energy needed does not locate in the designed position push the piston. Different fuel compositions have different autoignition temperatures, for example, methane is $540^{\circ} \mathrm{C}$ and for diesel fuel is $260^{\circ} \mathrm{C}$. Engine control is to be designed to the best performance while avoiding autoignition. Engine knocking happens when the engine fires a spark at the wrong timing with the incorrect amount of air to fuel ratio. It affects the engine performance and can cause damages to the engine. The latest technology of knock sensor can estimate which cylinder may knock and thus retard the ignition angle for the particular cylinder. This can be achieved through the use of knock control. The knock control system consists of knock sensor, signal processing unit, and the knock controller, which is integrated in ECU.

2.3. Intake Manifold Length and Volume. Geometry of intake manifold affects the flow of air/fuel mixture. The intake manifold length can be changed in some engines using adjustable mechanical parts $[6,7]$. It affects the mixture turbulence inside the combustion chamber and hence affects pressure and the burning velocity duration.

2.4. Start of Combustion. In term of engine control, spark plug can be controlled by ECU to decide whether the mixture needs to be ignited by spark. It gives more flexiblity to an engine with spark ignition and compression ignition combined, according to the engine condition.

The maximum pressure developed during combustion should occur at about 10 to 40 degrees beyond TDC depending on engine speed and engine load. The burning gas takes a comparatively long time to burn; therefore, the spark must be timed to occur well before TDC. Correct timing of ignition is important to give the highest engine power without knocking. If the timing of spark is too early, a rapid burning results engine knocks; conversely, a late spark causes slow burning and result in low engine power and poor fuel economy. The optimal moment of ignition is a function of several variables, such as the engine speed and the engine load.

2.5. Valve Timing and Valve Lift. The valves opening in the cylinder determine the amount of gas that may enter (intake valve) or exit (exhaust valve) to or from the combustion chamber [8]. It also determines the flow rate, and hence the pressure and temperature while combustion occurs. The effective compression ratio can be affected by the valves timing. In old engines, the duration of valves opening is fixed due to geometries of mechanical parts, that is, camshaft and valve lobe. Research has shown that engines perform differently at different rotation speeds and different loads [912]. Current variable valve timing systems (VVT) are limited to designed valve profile due to the dimension of lobe. There are two main methodologies in cam VVT, cam phasing which uses gear to shift the valve opening angle, and cam changing which shifts to different valve dimension when needed. The valve profile curve leads to a one-off open and close action. Electronic camless valve is under research for more valve timing flexibility for future use.

\subsubsection{Reaction on Compression Ratio Using Different Valve} Timing. The intake valve opening timing affects the effective compression ratio. The intake valve opening is designed to have the highest compression ratio in specification. With earlier or later intake valve closing, compression ratio is smaller than the specification. The amount of air or air/fuel mixture that enters into cylinder depends on the lift of the valve where maximal lift is reduced when the opening duration is reduced, and hence maximum volume is reduced. The compression ratio is an important parameter of engine torque.

2.5.2. Valve Overlapping. Valve overlapping happens when both intake and exhaust valve open for the same period [9], Figure 2. Typically, the period before the piston reaches the TDC in exhaust stroke and after the piston moves beyond the TDC in intake stroke. The advantage for valve overlapping is continuous variable valve timing (VVT) which provides adaptive adjustment to improve engine torque delivery across different revolution range $[11,13]$. When the engine speed is high, more air is needed for higher energy combustion; therefore, duration of intake valve opening needs to be longer. A portion of exhaust gas will suck back to the combustion chamber while the exhaust valve is opening, and hence increase the mixture pressure and temperature. At present, several vehicle manufacturers offer mechanical VVT, by means of cam phasing VVT. In this approach, the gear attached to the valve moves the position to change the two mechanical lobes and hence switch to different profiles. These profiles correspond to the amount of valve lifting.

Negative valve overlapping (NVO) consists of closing both valves for a period of time [5-8]. Exhaust valve closes before piston reaches the TDC, and intake valve opens after piston moves beyond the TDC. The concept is similar to the role of the exhaust valve in exhaust gas recirculation systems. When the intake valve opens, the hot residual gas heats up the fresh mixture, and the high temperature mixture is enhanced for compression ignition. The results, presented in [15], show that the injection timing is an important parameter. The new fuel injection strategy by injecting a portion of fuel during the negative valve closing interval and inject the rest in the intake stroke was also examined in [15]. 


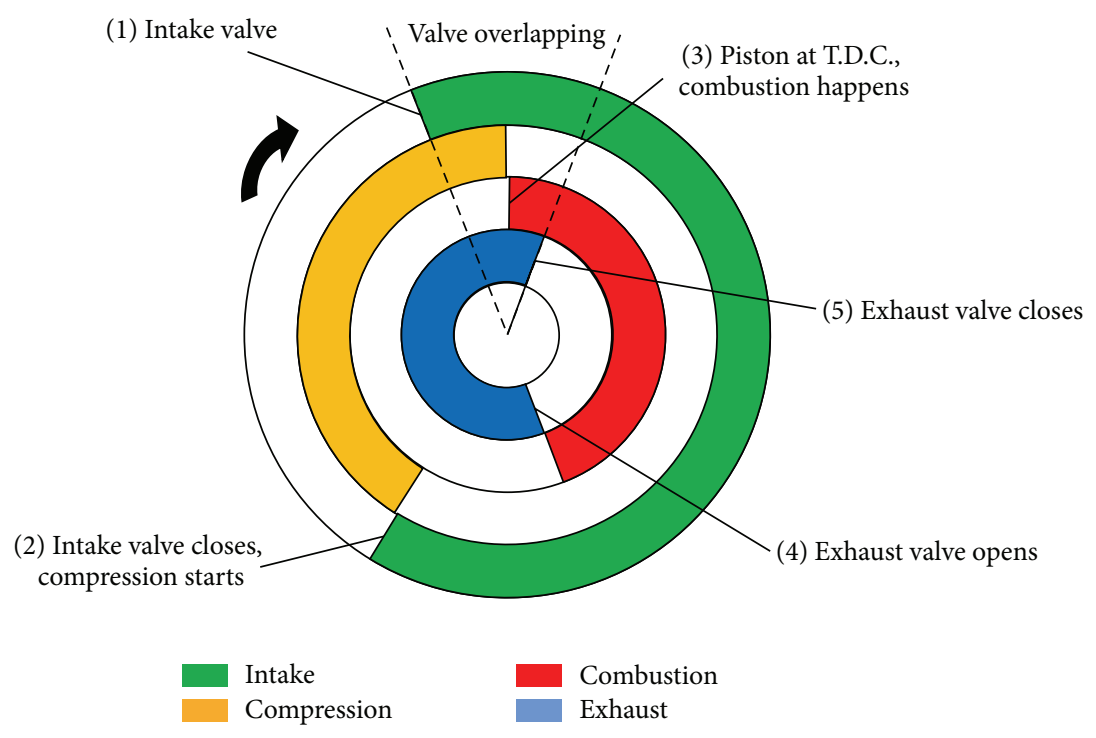

FIGURE 2: Valve overlapping in term of piston position.

2.5.3. Late Intake Valve Closing on Diesel Engine. Another case on other VVT approach is late intake valve closing (LIVC) which is found in diesel engine research. There are some researches investigating the performance on LIVC on diesel engines [16, 17]. The idea behind LIVC is to burn the mixture in a lower combustion temperature and hence to reduce nitrogen oxide (NOx). However, as a result, concentration of hydrocarbons (HC) and concentration of carbon oxide $(\mathrm{CO})$ increase. Then, emissions are reduced at low to medium engine loads and also less soot and particulate matter.

2.6. Exhaust Gas Recirculation. Exhaust gas recirculation (EGR) is based on the idea of sending a portion of the exhaust gas back to the cylinder for reburning, Figure 3. It can provide further control of the temperature and pressure of the fresh mixture by mixing it with exhaust gas. EGR system connects the exhaust manifold before the throttle. Fresh air is mixed with exhaust gas through the throttle and consequently the temperature of the gas rises. The amount of EGR is controlled by ECU. Research shows that the temperature of air is heated up by exhaust gas, which acts as a preheater before entering the combustion chamber at low speed. The effect is cancelled out at high speed and low load due to the decline in the temperature cycle, and hence no improvement is made [8]. Also, it affects significant improvement of performance such as NOx emission, engine break power, and fuel consumption. In [18], significant improvements were achieved in terms of performance by using $5 \%$ of EGR at low.

2.7. Compression Ratio. The compression ratio typically ranges from 8 to 12 for spark-ignition ICEs, and it is in the range of 12-24 for compression-ignition ICEs. When compression ratio is high, the fuel and air particles are closely packed together and obtain a higher explosive velocity during combustion, that is, better performance and better fuel consumption. However, it is limited by two considerations: material strength due to maximum stress at certain pressure and engine knock due to the maximum temperature during process exceeds autoignition temperature. There is some research on variable compression ratio system which changes geometries of combustion chambers $[4,5,19-21]$.

2.8. Length of Intake Manifold. Airflow is one of the main factors to simulate combustion. The pipe geometries control the air flow and affect the pressure and temperature of air/fuel mixture inside engine cylinders. Software treats the air flow as one-dimensional. The amount of air and the flow velocity entering the cylinders depend on its shape (circular or rectangular). In order to simplify the computational mesh, the duct or pipe is divided into discredited length where users can modify this parameter according to the duct length.

\section{Submodels}

A number of submodels are needed to provide a description of all relevant processes (burned gas composition, mass burning rate, heat transfer, blow-by, and others). Engine submodels are divided into various categories and include submodels for cylinder geometry and piston motion, combustion sub-model, friction and heat transfer submodels, and some others. Descriptions of submodels are based on data presented in user's guides $[2,3]$ and the literature $[22,23]$.

3.1. Engine Cycle. Engine cycle simulation model follows the changing thermodynamic and chemical state of the working fluid through the engine's intake, compression, combustion, expansion, and exhaust processes. The starting point for these cycle simulations is the first law of thermodynamics for an open system. The structure of this type of engine simulation is indicated in Figure 4. During each process, submodels are used to describe geometric features of the cylinder and 


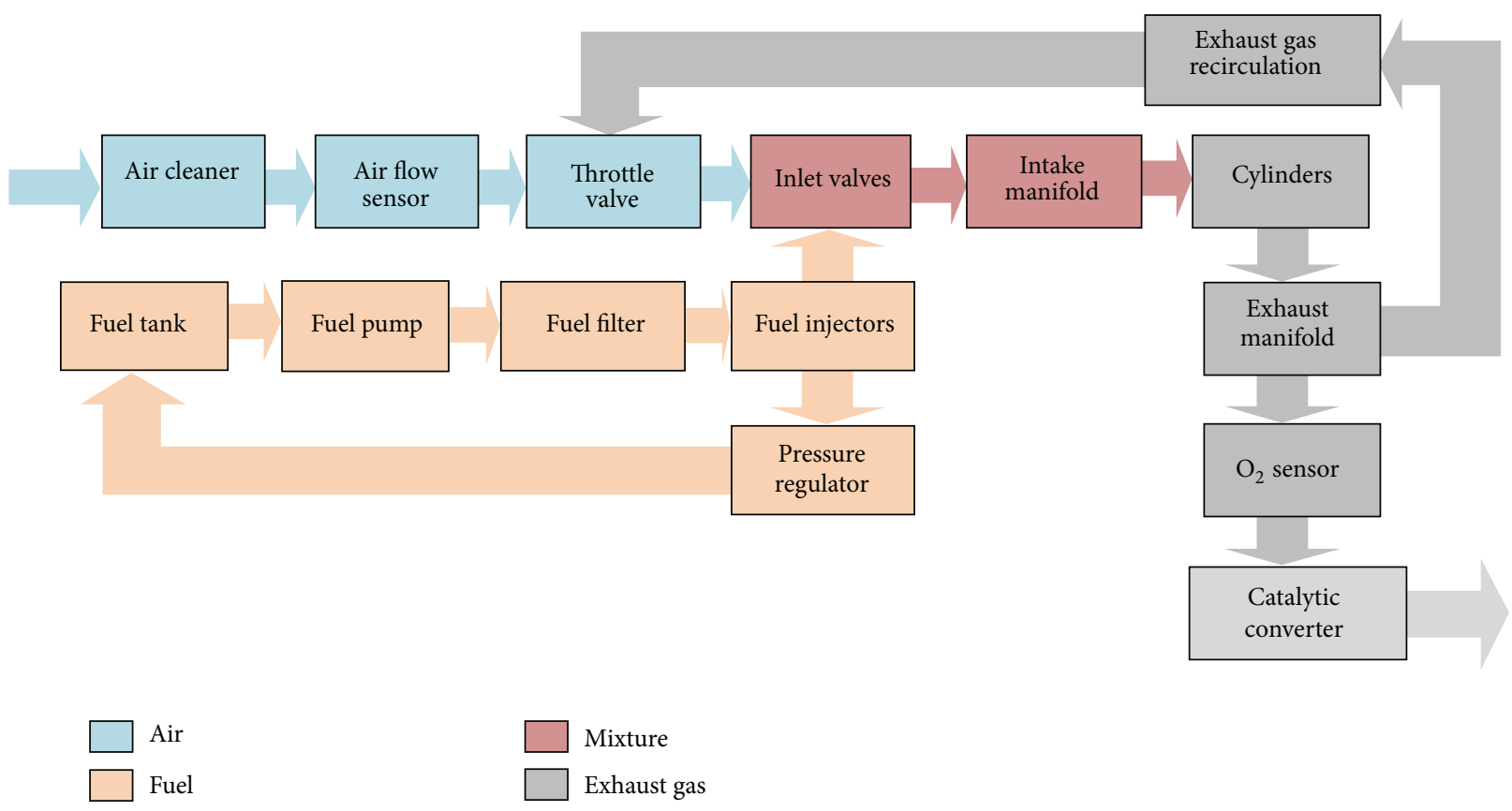

Figure 3: Air and fuel flow in ICE.

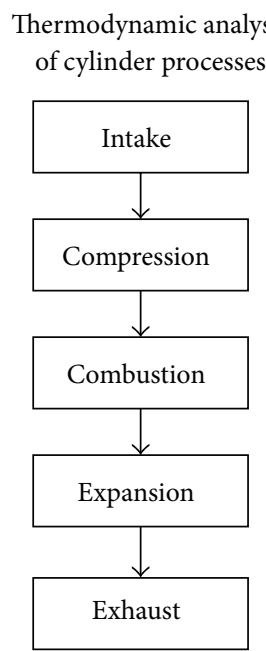

Phenomenological process models

$\rightarrow \begin{gathered}\text { Cylinder and } \\ \text { valve geometry } \\ \text { Thermodynamic } \\ \text { properties } \\ \text { Flow rate } \\ \text { Head transfer } \\ \text { Transport } \\ \text { properties } \\ \text { Combustion rate } \\ \text { Emissions } \\ \text { mechanism }\end{gathered}$

FIGURE 4: Structure of thermodynamic based simulation of ICE operating cycle.

valves/ports, the thermodynamic properties of unburned and burned gases, the mass and energy transfers across the system boundary, and the combustion process.

During intake and compression, the working fluid composition is frozen. The composition and thermodynamic properties are determined using the submodels. Mass flows across open valves are usually calculated using onedimensional compressible flow equations for flow through a restriction or filling and emptying models $[22,23]$. The more accurate unsteady gas dynamic intake and exhaust flow models are sometimes used to calculate the mass flow into the engine cylinder in complete engine cycle simulations when the variation in engine flow rate with speed is important (the disadvantage is much increased computing time). Heat transfer during intake and compression is calculated using one of the Nusselt-Reynolds number correlations for turbulent convective heat transfer $[22,23]$. The transport properties, viscosity, and thermal conductivity used in these correlations are obtained from semiempirical relations.

Many approaches to predict the burning or chemical energy release rate have been used successfully to meet different simulation objectives $[2,3,22,23]$. The simplest approach has been to use a one-zone model where a single thermodynamic system represents the entire combustion chamber contents, and the energy release rate is defined by empirically based functions specified as part of the simulation input. Quasi-geometric models of turbulent premixed flames are used with a two-zone analysis of the combustion chamber contents (an unburned and a burned gas region) in more sophisticated simulations of ICEs [22].

The expansion process is either treated as a continuation of the combustion process or, once combustion is over, uses the form of the mass, fuel, and energy conservation equations which hold during compression. The exhaust process uses conservation equations for a one-zone open-system model of the cylinder contents.

3.2. Cylinder Geometry. Geometric sub-model is used to define the topology of the combustion chamber as well as to specify geometric surfaces and volume zones used for heat transfer and combustion submodels. The cylinder volume depends on the engine geometry (bore, stroke, connecting rod length, and compression ratio) and is a function of crank angle and the rate of change of cylinder volume. 
The model used specifies the cylinder geometry as a piston, head, and cylindrical liner [22]. Both the piston and head surface area are assumed to be equivalent to the area derived from the bore diameter with multipliers of this area allowed in the Woschni heat transfer model.

3.3. Piston Motion. Piston motion sub-model is used to determine the instantaneous position of the piston in the cylinder and the volume of the combustion chamber as a function of crank angle. The piston position is fed to other submodels.

The crank-slider model is used to characterize the arrangement of mechanical parts designed to convert translational motion into rotational motion. The piston motion is defined by including geometric inputs for the cylindrical combustion chamber, crankshaft, and connecting rod. The position of piston is derived from basic trigonometry equations [22].

3.4. Air and Fuel Properties. Air consists of $21 \%$ oxygen and $79 \%$ of nitrogen (for each mole of $\mathrm{O}_{2}$ there are 3.76 moles of $\mathrm{N}_{2}$ ). Selected physical properties of oxygen and nitrogen are given in the textbooks and tables [23]. Extension of the analysis to different air mixtures encountered in practice is straightforward. The most frequent differences are the presence of water vapour, carbon dioxide, and argon in the atmospheric air. The amount of water vapour in the atmospheric air normally depends on temperature and degree of saturation.

In RW and MESC calculations, the fuel is a user-defined composition of $\mathrm{C}, \mathrm{H}, \mathrm{O}$, and $\mathrm{N}$ atoms (the most common hydrocarbon fuels have no $\mathrm{O}$ or $\mathrm{N}$ unless mixed with ethers or alcohols). In LESoft calculations, the fuel types are limited to those composed of $\mathrm{C}, \mathrm{H}$, and $\mathrm{O}$ atoms [2].

Combustion products are a mixture of some gases. The gas properties are based on the appropriate governing relations, for example, perfect gas equations for aironly thermochemistry or ideal/real gas equations for the thermochemistry of hydrocarbon/air mixture for general $\mathrm{C} / \mathrm{H} / \mathrm{O} / \mathrm{N}$ fuel types. The thermodynamic properties of the individual gases are calculated as functions of temperature with these properties being averaged as molar functions to give the overall properties of the mixture [22]. The gas property sub-model is based on polynomial curve fits to thermodynamic data for each species [22]. In a real gas model, the compressibility factor is calculated using empirical correlation [3]. For a gas mixture, the critical temperature and pressure and acentric factor are calculated according to the mixing rule. The real-gas enthalpy and internal energy are calculated from their ideal-gas counterparts, along with the specific heats at constant pressure and volume.

Dissociation effect on effective heat release is developed through the use of maldistribution factor [2]. The maldistribution factor is incorporated to allow for a reduction in effective caloric value of the fuel due to poor charge mixing and dissociation. A factor of 0 implies almost perfect mixing and a high effective caloric value for the fuel. A typical gasoline engine would have a maldistribution factor of between 1.0 and 3.0. Values less than 1.0 imply better combustion and may be appropriate for gas fuelled engines.

The coefficients of chemical reactions are determined from the equilibrium calculations [23]. Fuel evaporation and condensation are not taken into account in the calculations (these submodels are available in RW).

3.5. Heat Release Model. The amount of heat released during combustion transfer to energy pushes down the piston in an appropriate time. Burn rate is defined as the rate at which the fuel mass in the cylinder is consumed in the combustion process to become products of combustion. Regardless of the final state of the air/fuel mixture (emissions products, free radicals), the initial fresh air and fuel no longer exist in their natural states when combustion has completed.

The heat release rate is calculated using empirical heat release function derived from the Wiebe equation. The Wiebe model is widely used to describe the rate of fuel mass burned in thermodynamic calculations, and this model is available in all packages. The Wiebe function is [22]

$$
x_{b}=1-a \exp \left[\left(\frac{\theta-\theta_{s}}{\theta_{d}}\right)^{n}\right] \text {, }
$$

where $a$ is the range cover $10 \%-90 \%$ of mixture burned and $n$ is the efficiency of combustion. The combustion duration is defined as the number of crank degrees between $10 \%$ and $90 \%$ of mass fraction burnt. The combustion phasing is defined as the number of crank degrees after TDC firing at which $50 \%$ of the fuel has been burnt.

Wiebe model allows the independent input of function shape parameters, combustion duration, and combustion phasing which are functions of the type of fuel being used [22]. It is known to represent quite well the experimentally observed trends of premixed combustion. By adjusting the individual Wiebe function component shapes and their relative proportions through the fuel mass fractions, a complicated overall burn rate curve is defined. Varying the $50 \%$ burn point simply shifts the entire curve forward or backward. Varying the 10\%-90\% duration extends the total combustion duration, making the profile extend longer or compress shorter. Varying the Wiebe exponent shifts the curve to burn mass earlier or later.

The two-part Wiebe function takes into account the mass fraction burned in the premixed combustion period and the mass fraction burned during the diffusion combustion period $[2,3]$.

As an alternative to Wiebe combustion models, the user may choose to enter a complete profile of combustion [3]. This way allows the user to enter a cylinder pressure profile obtained from testing, internally derive a heat release profile using the applied heat transfer model and thermodynamic properties, and output a fuel mass burn profile for combustion calculations.

A more advanced sub-model, turbulent flame combustion model, calculates the rate of fuel burned using the turbulent flame speed and of instantaneous flame area [22]. It responds to changes in cylinder flows and in combustion 
chamber geometry. The model also provides spatial resolution as to the instantaneous flame location needed for heat transfer calculations.

A combustion model follows a constant combustion air to fuel ratio under the assumption that the air/fuel mixture is fully premixed. In certain engine designs (e.g., Spark Injection Direct Ignition engines), the fuel and air are not fully mixed at the start of combustion. The spark-ignition stratified sub-model is used in [3] to impose a combustion equivalence ratio that is different from the overall equivalence ratio of the cylinder, for the purpose of simulating a stratified charge mixture. This model allows combustion stoichiometry to vary during combustion and is used to improve accuracy of results for systems that add or remove air or fuel during combustion, since the system will respond more accurately to changes in cylinder contents. The spark-ignition stratified sub-model creates an adaptive mixture which begins at a user-entered equivalence ratio and adjusts as burn progresses to consume the available air.

3.6. Conduction. Conduction sub-model is used to calculate cylinder surface temperature. Accurate surface temperature improves boundary conditions for the in-cylinder heat transfer sub-model and is used to assist in engine component design. One conduction sub-model is available in MESC (it is referred to as "simple"), two conduction submodels are available in LESoft [2] (they are referred to as "simple" and "conduction"), and three submodels are implemented in RW [3] (they are referred to as "simple," "conduction" and "swing").

The "simple" engine conduction sub-model uses a predefined thermal network which represents the cylinder liner, cylinder head, piston, and intake and exhaust valves. This model enables the prediction of the surface temperature of the combustion chamber and heat rejection of the engine to the coolant. This model is offered by all packages.

Other conduction submodels, offered by LESoft and RW, use a more detailed predefined thermal network than "simple" model.

In the "conduction" sub-model used in LESoft and RW, the cylinder wall temperature is specified or calculated via a simple one-dimensional heat transfer calculations for cylinder head, piston and linear walls. The cylinder walls are assumed to have a wall thickness that is directly proportional to the bore. The heat transfer coefficients of coolant and cylinder head are constant value, and conductivity of material is specified by choosing material used. The cylinder head temperature is calculated as the area average of the wall temperature and the valve temperature. Valve head temperatures are calculated for both inlet and exhaust valves as a function of fuel type and air to fuel ratio. The piston temperature is assumed that it is equal to the area averaged cylinder head temperature. In the RW, this sub-model has more spatial resolution and also allows substituting portions of the predefined mesh with existing finite element models built using other commercial software [3].

The "swing" sub-model from the RW accounts for cyclic temperature transients on combustion chamber surfaces and other engine surfaces exposed to gases, which are produced by the peaked nature of the gas-wall heat fluxes [3]. This is especially relevant for in-cylinder surfaces with low conductivity where temperature fluctuation is quite high (100$200 \mathrm{~K})$.

The calculations presented are based on "simple" conduction model, and cylinder wall temperature is fixed in all calculations.

3.7. Heat Transfer Model. Two non-dimensional parameters, the Nusselt number and the Reynolds number, are used to estimate the heat transfer correlated with fluid conditions. Those two parameters vary in time, therefore heat transfer to and from the cylinder gases are calculated at every crank angle increment. These calculations require knowledge of wall area, wall temperatures, and surface heat transfer coefficient. The cylinder surface areas are calculated using surface area to bore area ratio which are a function of combustion system. The linear area is calculated at each increment by the piston displacement from TDC. Gas velocity depends on piston mean speed, amount of swirl, the amount of combustion and the gas turbulence [22].

Various heat transfer submodels are offered by each package for the calculation of the convective heat transfer coefficient in the engine cylinder $[2,3]$. The heat transfer models proposed by Annand, Woschni and Eichleberg are available in LESoft and MESC. Heat transfer models offered by the RW include Woschni, Annand and model referred to as "flow" model [3].

Woschni, Annand, and Eichleberg models are derived from a basic Nusselt number correlation for flow in pipes $[22,23]$. Each model employs coefficients that have been developed to best reproduce the heat transfer results obtained by experiment. The Woschni heat transfer sub-model is the most commonly used heat transfer model. It views the charge as having a uniform heat flow coefficient and velocity on all surfaces of the cylinder, and calculates the amount of heat transferred to and from the charge based on these assumptions. The Annand and Eichleberg heat transfer models are typically used as a mean of comparison for the results from the Woschni model. They are rarely used in practical applications [23]. Different from the Woschni model, where the increase in gas velocity in the cylinder during combustion is accounted for, the Annand model assumes a constant gas velocity equal to the mean piston speed.

The Woschni heat transfer correlation is [22]

$$
\mathrm{Nu}=0.0035 \mathrm{Re}^{0.8} .
$$

The heat transfer coefficient is

$$
h=128 h_{c} b^{-0.2} p^{0.8} T^{-0.53}\left(C_{1} u_{p m}+C_{2} T_{r} \frac{V}{V_{r}} \frac{p-p_{m}}{p_{r}}\right)^{0.8} \text {, }
$$

where $b$ is the bore $(\mathrm{m}), V$ is the cylinder volume $\left(\mathrm{m}^{3}\right), p$ is the cylinder pressure $(\mathrm{kPa}), T$ is the cylinder temperature $(\mathrm{K}), u_{p m}$ is the mean piston velocity $(\mathrm{m} / \mathrm{s})$, and $p_{m}$ is the motored cylinder pressure $(\mathrm{kPa})$. Subscript $r$ corresponds to the reference pressure $p_{r}(\mathrm{kPa})$, reference temperature 
$T_{r}(\mathrm{~K})$ and reference volume $V_{r}\left(\mathrm{~m}^{3}\right)$. User specific multiplier constant $h_{c}$ is 1 . The constant $C_{1}$ is 2.28 for combustion and is changed to 6.18 for scavenging. The constant $C_{2}$ defines the combustion term. Its value is $3.24 \times 10^{-3}$ in closed cycle, and 0 before combustion and scavenging.

The "flow" model, implemented in RW, predicts convective heat transfer from gases to combustion chamber walls, and its spatial and cyclic temporal variations are driven by the instantaneous mean and turbulent gas motions [3]. Prediction of heat transfer coefficient is linked to the fluid dynamics of combustion gases, determined by periodic piston motion, valve flows, injection process, combustion, motion of piston and chamber geometry. The multi-zone flow model solves differential equations for swirl and turbulence and an algebraic equation for squish in a number of combustion chamber flow zones. The heat transfer coefficient for each surface is obtained from the Colburn analogy of heat and momentum transfer and is directly linked to the effective velocities. One of the main benefits of this approach is that it captures the dependence of the heat transfer coefficient on the magnitude of instantaneous in-cylinder flow velocities. Another benefit is the improved ability of the model to represent the spatial nonuniformity of the heat transfer coefficients.

Thermal radiation from gases to surrounding combustion chamber surfaces is a significant component of heat transfer for diesel engines, due to soot formation during diesel combustion [22]. Instantaneous and mean levels of heat radiation are functions of the volume and distribution of burning gas, amount of soot present in the burning gas, combustion chamber geometry, and surface emissivity and temperature. The submodels employed in the radiation model calculate the soot loading in the burned zone, volume of the radiating burned zone and radiation temperature.

3.8. Friction. The Chen-Flynn friction model is used to calculate the work done by friction in the engine and accompanying systems $[2,3]$. Friction model takes into account engine speed, mean piston speed, maximum cylinder pressure and compression ratio. The Chen-Flynn correlation has a constant term (for accessory friction), a term which varies with peak cylinder pressure, a term linearly dependent on mean piston velocity (for hydrodynamic friction), and a term quadratic with mean piston velocity (for windage losses).

3.9. Blow-By. Blow-by occurs when a portion of gas escapes through the gap between piston and cylinder wall into the crankcase [22]. The consequence is the pressure inside the cylinder decrease by a portion. This is also takes into account when sub-model calculates the enthalpy. The blow-by model calculates how much gas is removed from the cylinder during the cycle and blows by the cylinder's rings, optionally into the crankcase.

In MESC calculations, the fraction of blow-by is specified with initial value of 0.8 . In RW calculations, blow-by submodel assumes the net gas flow past the first ring in zero and enables the thermodynamic model for the first crevice [3]. The input parameters for the model are cold piston liner clearance and distance of the top ring from piston top. During compression, the air/fuel mixture is packed into the crevice volume (absorption process) allowing unburned hydrocarbons to escape the combustion process occurring in the main chamber. The absorbed unburned hydrocarbons return to the cylinder during expansion as a source of hydrocarbons emissions.

3.10. Emissions. Emissions submodels are used to calculate the in-cylinder formation and destruction of common engine emissions species [22, 23]. Emissions submodels for the engine include $\mathrm{CO}, \mathrm{HC}$, and NOx. The $\mathrm{CO}$ emissions sub-model predicts $\mathrm{CO}$ production during combustion and exhaust in an engine cylinder element. The $\mathrm{HC}$ emissions sub-model predicts HC production during combustion and exhaust in an engine cylinder element as well as in the flow network. The NOx emissions sub-model predicts NOx production during combustion and exhaust in an engine cylinder element.

The emissions submodels are available in all packages but they are not used in the simulations presented.

3.11. Valve Motion. Valve motion is specified by means of a few simple parameters such as diameter, maximum lift, and duration of opening and closing ramps [22, 23]. The lift valve sub-model defines a lift profile using polynomial lift curves. The valve lift duration is specified by the number of crank degrees between valve opening and valve closing. The valveflow model assumes a steady, a diabatic, and reversible flow of an ideal fluid through a duct. The valve flow in an engine is not an ideal flow, and the discharge coefficient is introduced to account for real gas effects. The mass flow through the valves depends on the effective open area, pressure ratio, upstream pressure, specific heat, upstream temperature and ratio of specific heats.

3.12. Scavenging. The gas exchange process in the four-stroke engine is driven primarily by the piston motion, and a fully mixed scavenging model is most commonly used [22]. With the perfect mixing model any charge gas entering the cylinder is instantaneously and homogeneously mixed with the gas currently in the cylinder.

3.13. Network Model. Flow elements are used to construct the flow network, which is the primary part of any model. The collection of flow elements available are organized into groups, representing element types. These elements are similar in various packages $[2,3]$.

Ambient element is used as flow sources and sinks in a model and attach to the rest of the flow network via a single duct. This is most-commonly used element to represent an infinite reservoir at standard atmospheric conditions.

Cylinder elements is typically used to model the cylinder of an engine, however additional elements are included to model piston compressors and crankcases. Cylinder element is zero-dimensional and simply represents a volume changing with time. Cylinder connects to multiple flow elements via 
valves and usually require numerous submodels in order to correctly represent the desired system.

Duct element represents a portion of a flow network which is long (in respect to cross-sectional area) creating onedimensional flow. It is automatically discretized into a series of computational cells based on a discretization length. A duct must be connected at each end to one ambient or cylinder element.

A fuel/air injector element injects into a cylinder enough fuel to meet a specified fuel/air ratio based on the total air flow through engine from the previous engine cycle. The achieved fuel/air ratio is more or less than the target ratio based on some of the air or fuel exiting through the valves.

3.14. Capabilities. Cylinder and plenum are zero-dimensional elements in that they have properties of mass, pressure, temperature and volume but not length. The conditions within these elements are calculated at each crank angle by solving the mass equation and the energy equation derived from the first law of thermodynamics.

The mass equation accounts for changes in in-cylinder mass due to flow through valves, and due to fuel injection. A separate accounting is made for fluxes of air, fuel and products of combustion. The energy equation equates the change of internal energy of in-cylinder gases to the sum of enthalpy fluxes in and out of the chamber, heat transfer, and piston work.

There are two options: single zone and two zone. In the one-zone model, implemented in LESoft [2], the whole cylinder is treated as one region, while in the two-zone model, implemented in RW and MESC, the cylinder is divided to two regions: an unburned zone and a burned zone which share a common pressure [3]. The two-zone model is used to capture in more detail the processes taking place during the combustion period. All combustion models may be used in either single or two-zone model, but emissions models generally require the two-zone model [22].

Table 1 shows the capabilities of different engine simulating software. The submodels used in simulations are only presented in the table.

3.15. Development of Engine Models. The solver reads a model from a main input file which contains all data required for a simulation (the model network, initial conditions for the flow field and all control data for the run). The solver produces an output file when run. The output file contains information, important in understanding the input, run-time processing and output of a model (time step output, engine summary, fuel burn progress summary, engine geometry, operating conditions, engine cylinder heat transfer, performance). A general flow diagram for the development of a model is shown in Figure 5.

The basic engine data include engine geometry (bore, stroke, connector rod length, compression ratio), engine inertia (mass and inertia of various components), cylinder and valve event phasing. Initial conditions such as exhaust temperatures, intake temperatures, and wall temperatures need to be input as reasonable values. The motion of the
TABLE 1: Capability of engine simulation software.

\begin{tabular}{lccc}
\hline $\begin{array}{l}\text { Submodel/controlled } \\
\text { parameter }\end{array}$ & LESoft & RW & MESC \\
\hline Geometry & + & + & + \\
$\quad$ Compression & + & + & + \\
ratio & $\mathrm{C} / \mathrm{H} / \mathrm{O}$ & $\mathrm{C} / \mathrm{H} / \mathrm{O} / \mathrm{N}$ & $\mathrm{C} / \mathrm{H} / \mathrm{O} / \mathrm{N}$ \\
Air/fuel properties & + & + & + \\
$\quad$ Fuel composition & + & + & + \\
Air/fuel ratio & - & - & - \\
Injection timing & Wiebe/Others & Wiebe/Others & Wiebe \\
Heat release & + & + & + \\
$\quad$ Ignition timing & Simple & Simple & Simple \\
Conduction & Woschni & Woschni & Woschni \\
& Annand & & \\
Heat transfer & Eichelberg & & + \\
& + & + & + \\
Friction & Simple & Simple & Percentage \\
Blow-by & + & + & + \\
Emission & Simple & Simple & Simple \\
Valve motion & + & + & + \\
Valve lift & Simple & Simple & Simple \\
Valve timing & & & + \\
Scavenging & + & + & +
\end{tabular}

piston is calculated based on the data specified for bore, stroke, and connecting rod length. The clearance volume is calculated based on the compression ratio.

Once the basic inputs are defined, the advanced inputs need to be defined. These inputs are port flow coefficients, valve lift per crankshaft rotation, combustion and heat transfer modeling (types of models to be used for representing the combustion and heat transfer processes and the surface areas and temperatures of various components within the cylinder, phasing of cylinder firing with respect to TDC). Some intuition is used to determine the parameters due to the large difference in engine operating speed and difference in engine type.

To define the operation of the cylinder head, the valve lift per incremental camshaft rotation is defined. The results of valve lift versus incremental camshaft rotation are related to crankshaft rotation based on published valve opening points with reference to crankshaft position. Flow versus valve lift is defined. The input is in the form of flow coefficients or discharge coefficients taken from the empirical data [22].

Once these basic and advanced inputs have been satisfied, the simulation format is specified. Convergence detection allows the package to move on to the next case once a userspecified tolerance for convergence (tolerance is about $1 \%$ ) towards a solution is attained on the active case. Simulation duration sets the number of cycles for the engine to run before settling on a solution. If auto-convergence is enabled, the package will move on to the next case once convergence is reached regardless of the number of cycles specified. If convergence is not reached by the number of specified cycles, 


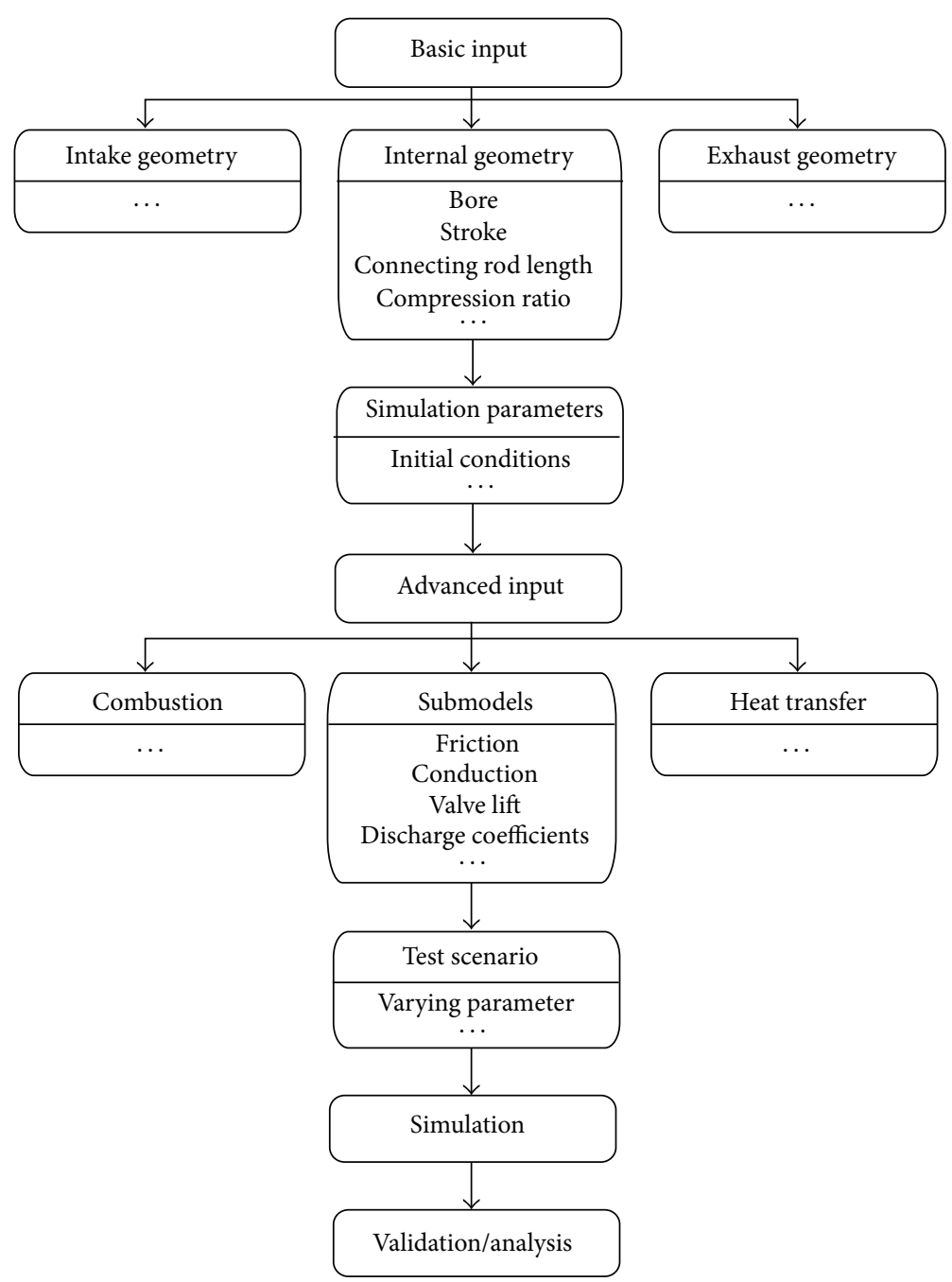

FIGURE 5: Development of engine model.

the package will output a warning to let the user know that convergence was not reached within desired tolerances and will continue on to the next case.

\section{Results and Discussion}

Three engine models are designed with various packages, and engine operating parameters and submodels are chosen to perform the tests.

4.1. Scenarios of Tests. The tests with three packages, RW, LESoft, and MESC, are performed for fixed engine geometry and different engine operating parameters. Test 1 is focused on comparison of the results computed with various packages and reference results presented in [23]. Ignition timing, air to fuel ratio and compression ratio are varied in the Test 2, Test 3 , and Test 4, respectively. Profiles of pressure and temperature are plotted for various tests, and discrepancies of the results computed with various packages are discussed.

The engine model, used in the tests, represents a simple one-cylinder four-stroke engine. The engine geometry and engine operating parameters, which are fixed in the tests, are specified in Table 2. The engine cylinder has a bore of $0.1 \mathrm{~m}$, stroke of $0.08 \mathrm{~m}$ and connecting rod length of $0.15 \mathrm{~m}$. The engine speed is fixed at $2000 \mathrm{rpm}$. The intake temperature and pressure are $300 \mathrm{~K}$ and 1 bar. The exhaust temperature and pressure are $700 \mathrm{~K}$ and 1 bar. Initial temperature and pressure of the cylinder are $350 \mathrm{~K}$ and 1 bar. The fuel is gasoline $\left(\mathrm{C}_{8} \mathrm{H}_{18}\right)$ with an equivalence ratio of 0.8 . The Wiebe combustion model is used in all tests with parameters which fit many experimental data $[22,23](a=5$ and $n=3)$. The burn duration is fixed at 60 degrees although crank angle corresponding to the start of combustion may be varied in calculations. Heat transfer in the cylinder is described using Woschni correlation $\left(C_{1}=2.28\right.$ for combustion and $C_{1}=6.18$ for scavenging). The averaged cylinder wall temperature is fixed at $420 \mathrm{~K}$. Exhaust valve opens and closes at 170 and 390 degrees, and intake valve opens and closes at 330 and 550 degrees (valve overlapping).

The engine operating parameters, which are varied in the tests performed, are presented in Table 3. All engine operating parameters are fixed for the Test 1 . The burning 
TABLE 2: Geometry of engine and fixed engine operating parameters.

\begin{tabular}{lc}
\hline Parameter & Value \\
\hline Bore, $\mathrm{m}$ & 0.10 \\
Stroke, $\mathrm{m}$ & 0.08 \\
Connecting rod length, $\mathrm{m}$ & 0.16 \\
Engine speed, rpm & 2000 \\
Intake pressure, bar & 1 \\
Intake temperature, $\mathrm{K}$ & 350 \\
Exhaust pressure, bar & 1 \\
Exhaust temperature, $\mathrm{K}$ & 700 \\
Fuel & $\mathrm{C}_{8} \mathrm{H}_{18}$ \\
Equivalence ratio & 0.8 \\
Combustion model & Wiebe model \\
Combustion duration, deg & 60 \\
Heat transfer model & Woschni model \\
Wall temperature, $\mathrm{K}$ & 420 \\
Valve timing, deg & EVO 170, EVC 390, IVO 330, IVC 550 \\
\hline
\end{tabular}

TABLE 3: Varied engine operating parameters.

\begin{tabular}{lcc}
\hline Test & Varied parameter & Interval of values \\
\hline Test 1 & No & Fixed values \\
Test 2 & $\begin{array}{c}\text { Ignition timing, } \\
\text { deg }\end{array}$ & From -60 to 10 with step 10 \\
Test 3 & Air to fuel ratio & From 10 to 18 with step 2 \\
Test 4 & Compression ratio & From 6 to 14 with step 2 \\
\hline
\end{tabular}

initiation time is varied in Test 2, air to fuel ratio is varied in Test 3 , and compression ratio is varied in Test 4 .

Detailed verification and validation of submodels describing chemical composition of combustion products, heat transfer, friction and combustion processes, and gas dynamics of intake and exhaust systems have been performed. The results obtained have been compared with the reference data presented in $[22,23]$, and these results are not presented in the paper. Main attention of the study presented is focused on predicting cylinder pressure and temperature distributions with various packages and use of the engine simulation packages in development of control systems.

4.2. Engine Models. Three packages are used to model the cycle of one-cylinder four-stroke engine, and three engine models are designed with various packages. The engine model itself consists of the flow network designed using flow elements, submodels applied to the flow elements, and a control network, built using control elements. The piping and manifolds of the intake and exhaust systems are also modelled using the flow elements. The flow network and intake and exhaust networks are then linked together through engine elements and submodels.

4.2.1. Ricardo Wave. The engine model, designed with RW, is shown in Figure 6. The engine model consists of cylinder

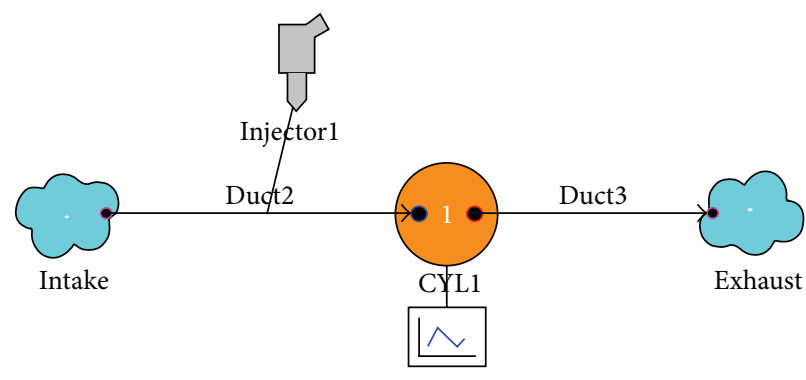

FIGURE 6: Engine model designed with RW.

("cyll" element) and intake and exhaust networks each of which is designed using ambient and duct elements. The intake network consists of "Intake" ambient element containing a fresh air at the temperature of $350 \mathrm{~K}$ and pressure of 1 bar, and "duct2" duct element connecting manifold and cylinder. The exhaust network consists of "Exhaust" ambient element containing exhaust gases at the temperature of $700 \mathrm{~K}$ and pressure of 1 bar, and "duct3" duct element connecting cylinder and manifold. The fuel injector ("injectorl" element) is installed in the middle of the connecting duct ("duct2" element). Fuel is mixed with fresh air and premixed air, and fuel mixture enters the cylinder. The cross-sectional area of intake pipe is $35 \mathrm{~mm}$ ("duct2" element), and crosssectional area of exhaust pipe is $28 \mathrm{~mm}$ ("duct3" element). The maximum valve lift is $9 \mathrm{~mm}$, and the default lift profile is used. The friction and blow-by parameters are by default. Other engine operating parameters are specified in Table 2.

4.2.2. Lotus Engine Simulation. The engine model, designed with LESoft, is shown in Figure 7. The engine model consists of the cylinder ("CYLl" element), and intake and exhaust networks each of which is designed using three elements representing connector, port, and valve. The inlet connector ("INL1" element) contains fresh air at the temperature of $350 \mathrm{~K}$ and pressure of 1 bar. Fresh air goes through an intake port ("PORT1" element) with the diameter of $35 \mathrm{~mm}$. The intake port is connected with the intake valve ("PVAL1" element). The exhaust gases leave the cylinder through the exhaust valve ("PVAL2" element) and exhaust port ("PORT2" element) with the diameter of $28 \mathrm{~mm}$. The exhaust port is attached to the exit pipe ("EXT1" element), and the boundary conditions for exhaust gases are fixed at the temperature of $700 \mathrm{~K}$ and pressure of $1 \mathrm{bar}$. The maximum valve lift for both intake and exhaust valves are $9 \mathrm{~mm}$, and the lift profile is "fast lift" profile. The friction and blow-by parameters are by default. Other engine operating parameters are specified in Table 2.

4.2.3. Matlab Engine Simulation Code (MESC). The engine model, implemented with in-house package, MESC, is designed using flow and control elements specified in the text file (there is no graphics user interface, as this is in-house package). The friction and blow-by parameters are the same as in RW and LESoft engine models. Other engine operating parameters are specified in Table 2. 


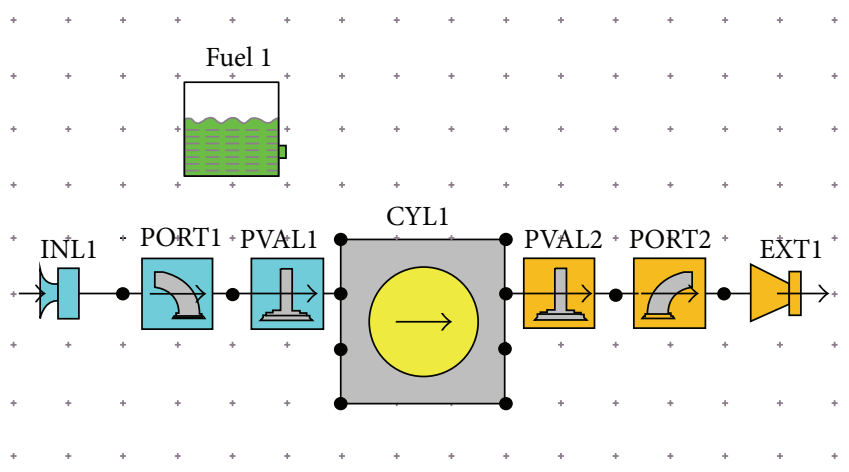

Figure 7: Engine model designed with LESoft.

4.3. Comparison with Reference Results. The reference test is intended to match input parameters and settings for three packages as similar as possible. The engine models, designed with various packages, have been validated by comparing the results computed with reference results presented in [23]. The geometric parameters and operating parameters of engine are shown in Table 2, and some other input parameters, which are specific for this test, are presented in Table 4 . The engine is a basic one-cylinder engine. The ignition timing is 35 degrees prior to TDC in the combustion stroke, compression ratio is 10 , and air to fuel ratio is 14.7 .

The accuracy of the curve coefficients that are used to describe the thermodynamic properties of the fuel, air, and combustion products is established through internal consistency check and comparison to well-established properties at the reference conditions ( $T=298.15 \mathrm{~K}$ and $p=1$ bar). Based on these results, it is concluded that the fundamental thermodynamic properties of the fuel, air, and combustion product species are in agreement with published results in [23] to within the scatter of those results (typically less than $1 \%)$.

The pressure and temperature distributions in the engine cylinder, computed with various packages, are compared with the tabulated outputs from [23]. Comparisons between the results computed and those from [23] confirm that three packages produce reasonable data.

The pressure profiles in the compression and combustion strokes are presented in Figure 8. The pressure distributions are started with crank angle of -180 degrees when the piston is at BDC. The pressure increases when the piston moves up to compress the air and fuel mixture. Ignition starts at -35 degrees before TDC when the combustion model starts to estimate the heat generated during combustion. The pressure rises due to the heat added to the compressed gas. The energy generated in the combustion process pushes piston down, volume increases and pressure drops. The results, predicted with RW and LESoft, are very close. The pressure profile, predicted with MESC, has a slightly delay in the maximum pressure point (this shift is about 2 degrees), and the maximum pressure level is about $6 \%$ lower compared to RW and LESoft results. Comparing the results obtained with the reference results of [23], calculations give delay in the maximum pressure point (this shift is about 10 degrees for
TABLE 4: Input parameters for reference test.

\begin{tabular}{lc}
\hline Parameter & Value \\
\hline Ignition timing, deg & -35 \\
Compression ratio & 10 \\
Air to fuel ratio & 14.7 \\
\hline
\end{tabular}

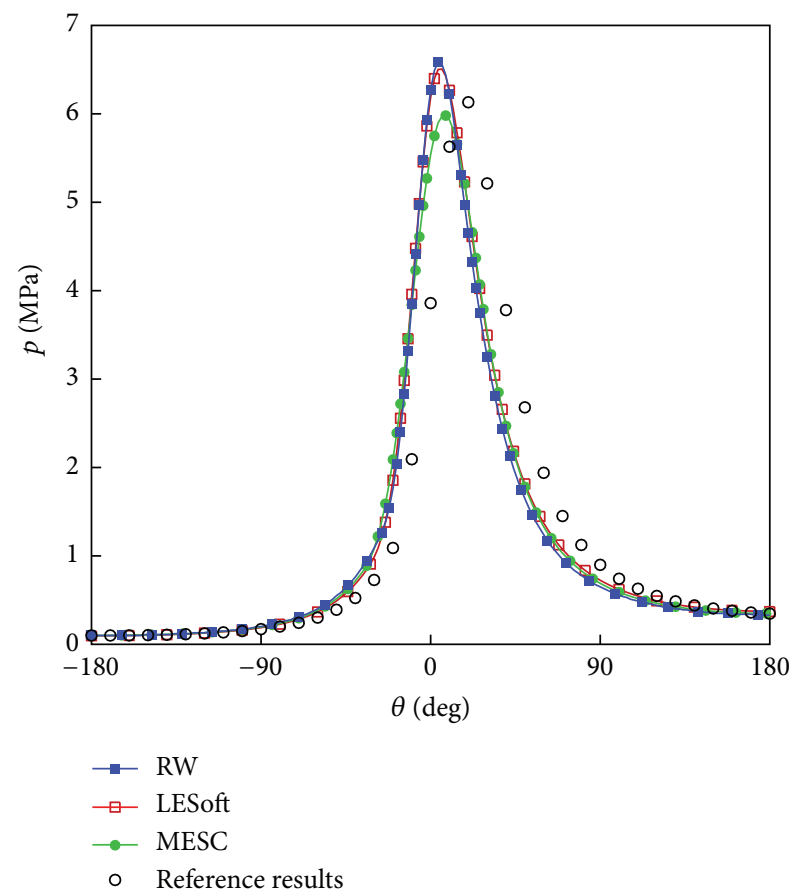

FIgURE 8: Comparison of pressure profiles with reference data of [23].

RW and LESoft calculations, and it is about 8 degrees for MESC calculations), although the maximum pressure level, predicted with various packages, is close to reference data (discrepancy is about 3\% for all packages).

The results, presented in Figure 9, show the distributions of temperatures of burned and unburned mixture during compression and combustion strokes. Ignition starts at -35 degrees before TDC, when the combustion model starts to work in the burned zone. Calculations in the unburned zone continue without addition of heat due to combustion. Ignition duration is 60 degrees, and work of combustion model is finished at 25 degrees after the TDC. The temperature profiles corresponding to the burned and unburned mixtures are overlapped during the combustion interval (it is fixed at 60 degrees). The calculations after combustion depend on the temperature level reached in the burned zone. The reference results from [23] are plotted with the temperature step of 10 degrees. The reference results show a slightly lower level of temperature in the unburned zone and slightly higher level of temperature in the burned zone compared to the results computed with RW and MESC. Calculations with LESoft are based on one-zone model allowing prediction of averaged temperature in the engine cylinder. Discrepancy of the results computed with various packages may be explained by the 


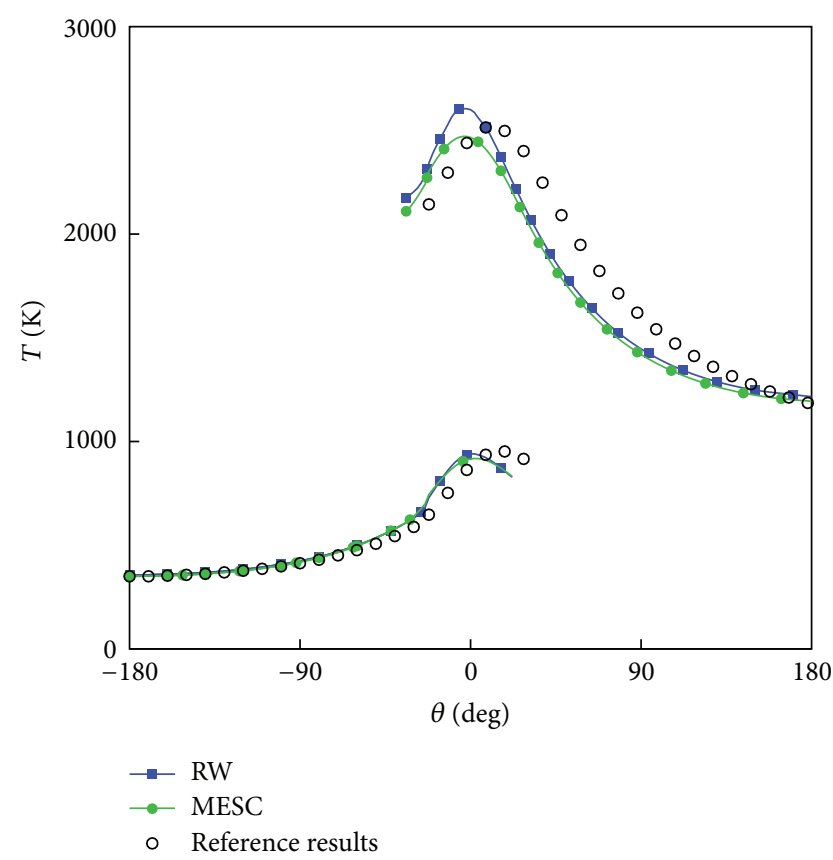

FIGURE 9: Comparison of unburned and burned temperature profiles with reference data of [23].

different implementation of combustion models (there are some parameters and settings which are not controlled by the user) and small discrepancy in physical and chemical properties of fuel and combustion products.

The results, presented in Figure 10, show distributions of temperature averaged over burned and unburned zones (averaged temperature is not presented in [23] but may be calculated using results computed in burned and unburned zones). LESoft calculations are based on one-zone model, whereas results predicted with RW and MESC calculations are based on two-zone models. The temperature profiles out of combustion interval, which is fixed at 60 degrees, are very close for all packages. As for the profiles of temperature, presented in Figure 10, main discrepancy of the profiles of averaged temperature is related to the results corresponding to the combustion interval. LESoft and RW results are similar, although there is a slight delay in the peak of temperature occurring in RW calculations compared to LESoft calculations. MESC calculations have a visible delay in the occurrence of peak of averaged temperature and the maximum level of temperature which are about 3 degrees and $5 \%$, respectively.

The main factor affecting the pressure and temperature distributions in the engine cylinder is calculation of heat generated during combustion (combustion sub-model). Although the heat release equation is matched in various packages considered, other factors may affect the results computed. In MESC and reference calculations from [23], the heat release escapes through the piston and cylinder wall gap using a blow-by fraction of 0.8 , whereas RW and LESoft use default settings. Other factor affecting pressure and temperature profiles is heat transfer sub-model, which

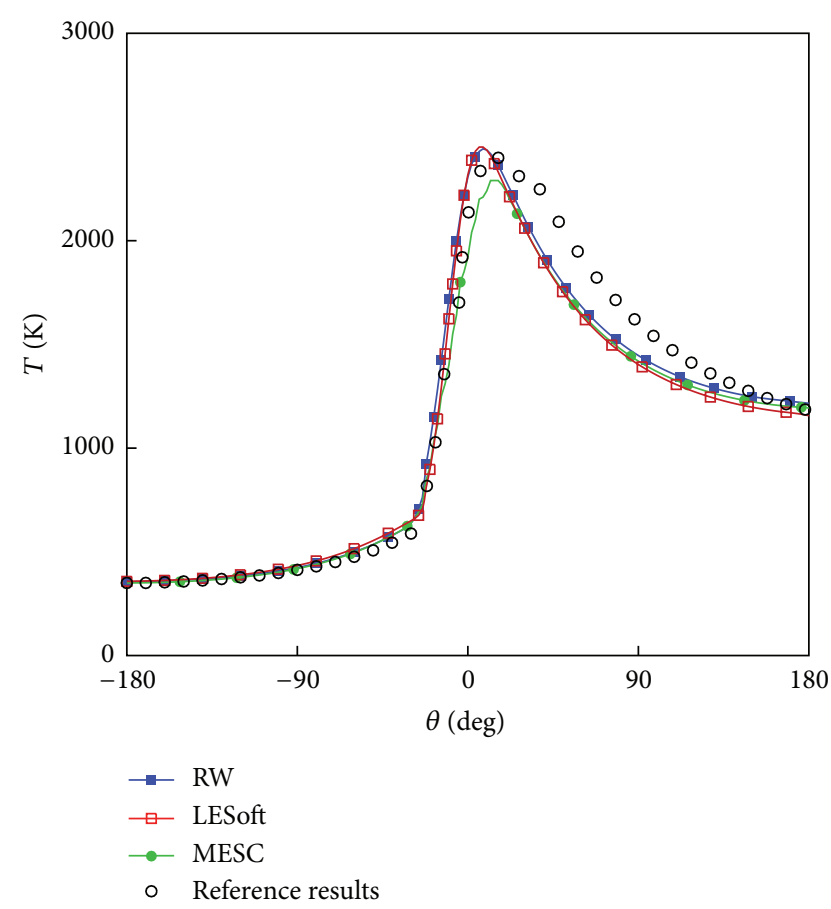

FIGURE 10: Comparison of averaged temperature profiles with reference data of [23].

TABLE 5: Input parameters for varying ignition timing test.

\begin{tabular}{lc}
\hline Parameter & Value \\
\hline Ignition timing, & $-60,-50,-10,0$ \\
deg & 10 \\
Compression ratio & 14.7 \\
Air to fuel ratio & EVO 170, EVC 330, IVO 390, IVC 550 \\
Valve timing, deg &
\end{tabular}

is not flexible to modify in RW. Inlet and exhaust pipe dimensions also affect the flows of air and combustion products in the cylinder, but these factors are not considered in the calculations presented.

The indicated mean effective pressure from the calculations with MESC package is $0.9528 \mathrm{MPa}$, whereas a value of $0.9510 \mathrm{MPa}$ was obtained in [23] (a difference is about $0.2 \%$ ). Discrepancies in the conservation of mass and energy are about $0.05 \%$ for all calculations.

4.4. Varying Ignition Timing. Ignition timing is one of the most important parameters in engine control. In this test, different ignition timings are examined in terms of distributions of pressure and temperature in the combustion chamber. The geometric parameters and operating parameters of engine are shown in Table 2, and some other input parameters, which are specific for this test, are presented in Table 5.

The pressure distributions, predicted with three packages, are presented in Figure 11. The results obtained are very similar in early ignition timing. For the late ignition timing, the discrepancy of the results computed is more significant in 

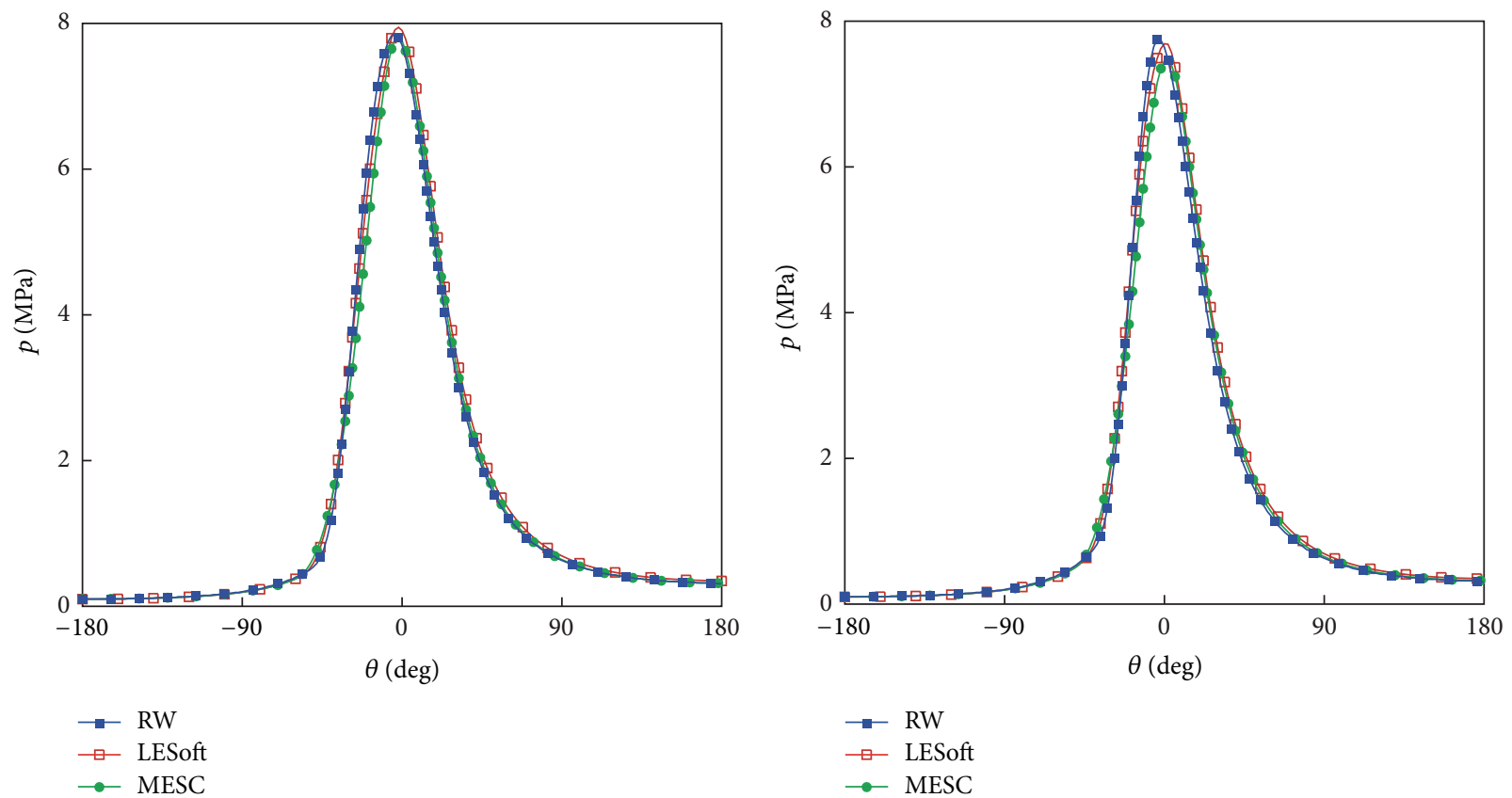

(a)

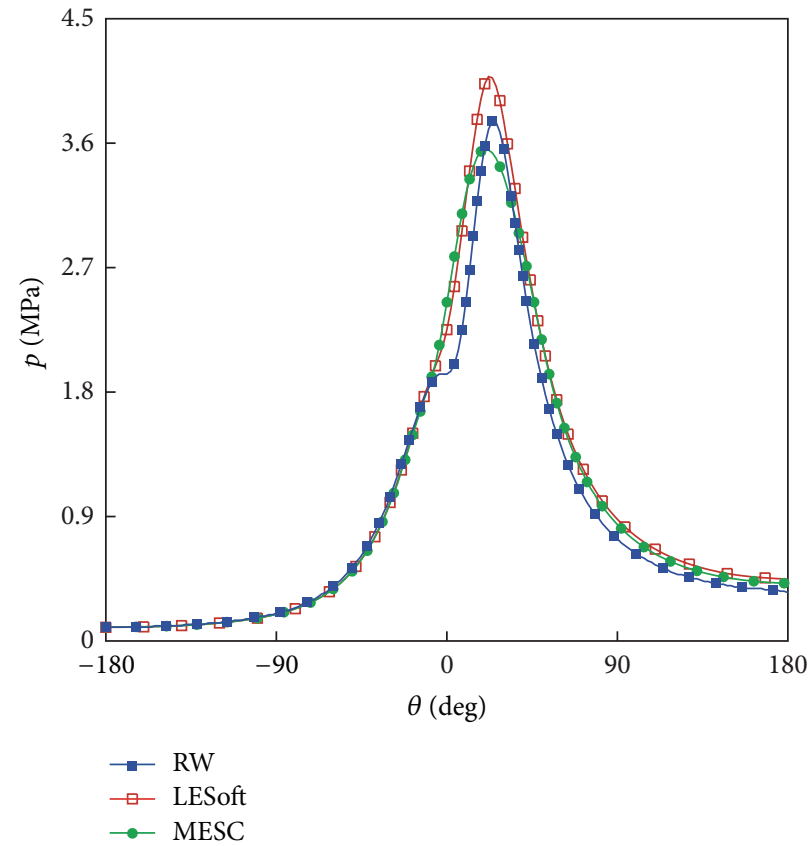

(c)

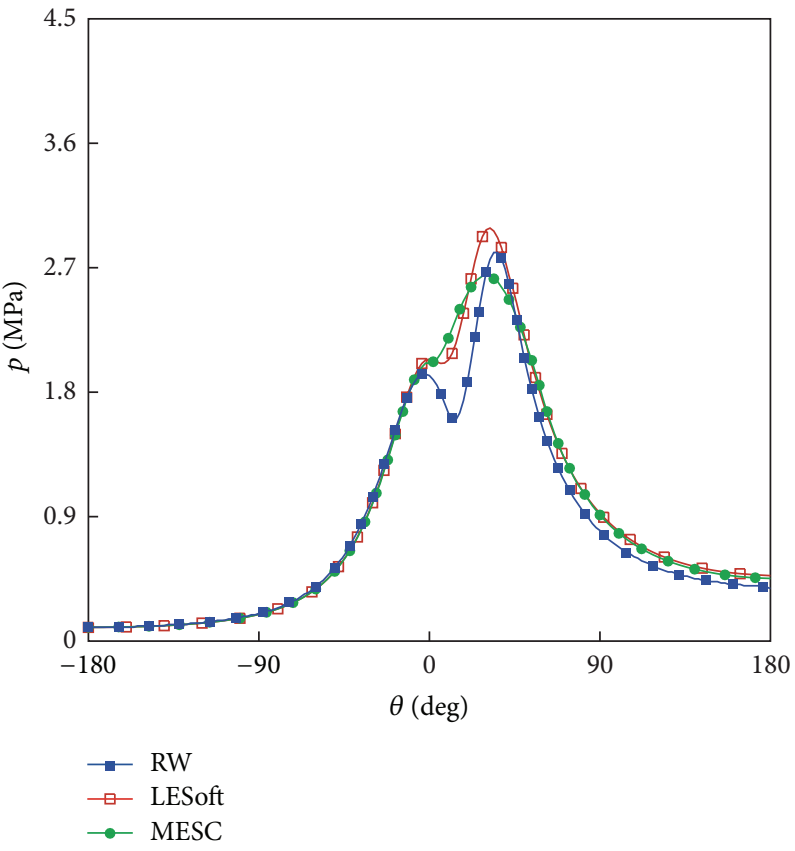

(d)

FIGURE 11: Profiles of pressure for different ignition timing of -60 (a), -50 (b), -10 (c), and 0 (d) degrees.

terms of occurrence of pressure peak. LESoft gives the earliest self-ignition which takes place just before crank angle of -10 degrees. The pressure peaks, predicted with RW and MESC calculations, are in a good agreement.

There is a small difference in the maximum value of pressure, predicted with various packages. The location of pressure peak, predicted with three packages, is shown in
Table 6. RW calculations give the earliest location of pressure peak, and LESoft calculations give the latest location of pressure peak in terms of crank angle.

The profiles of averaged temperature are shown in Figure 12. The profiles of temperature are very similar for three packages. There are, however, small differences in the maximum level of temperature and small differences in 


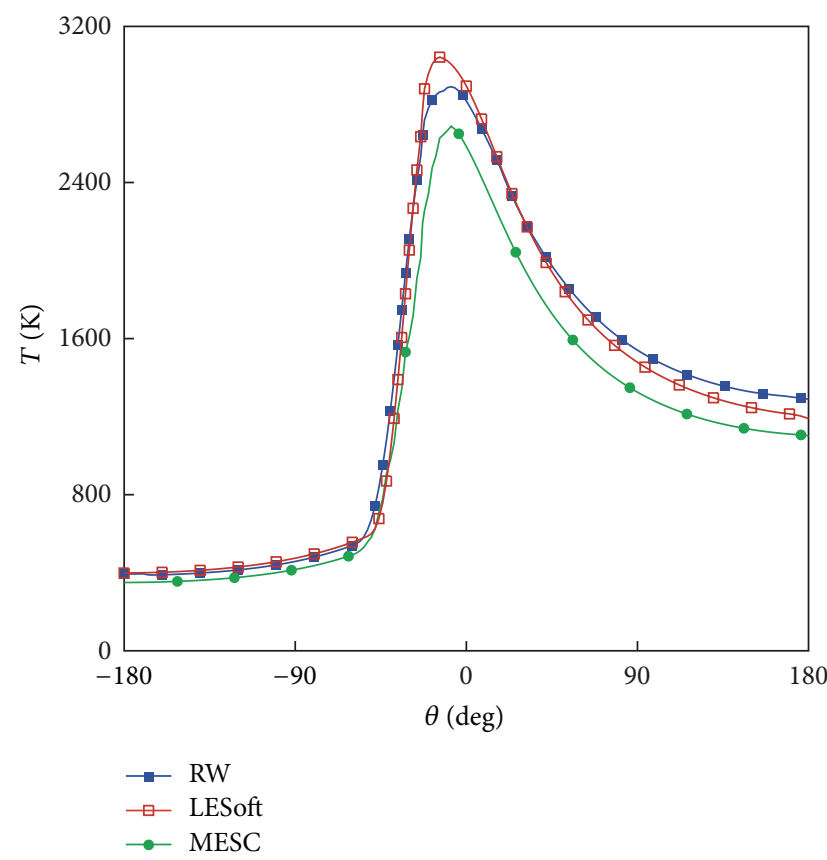

(a)

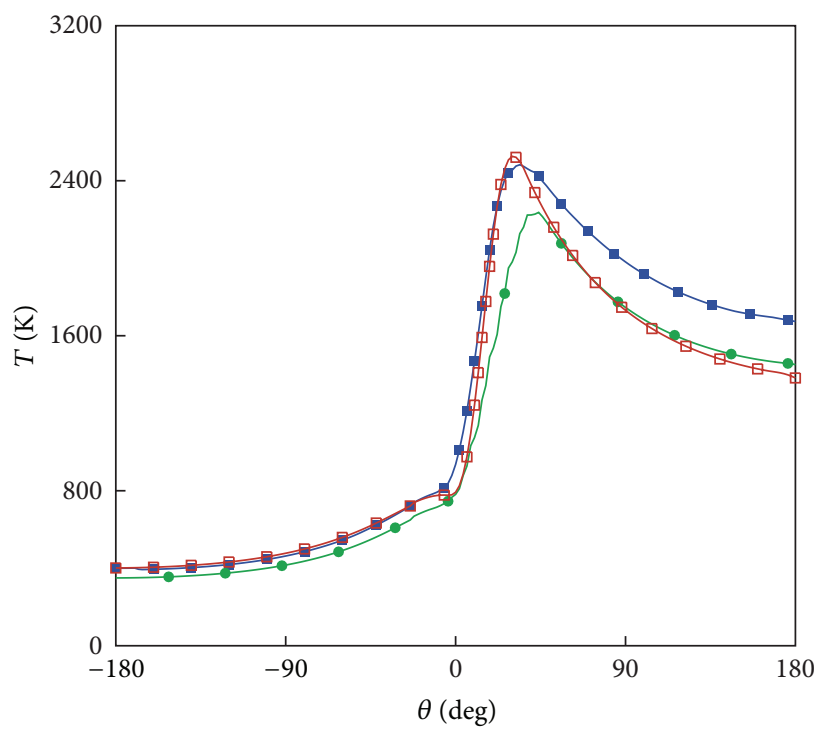

$\begin{array}{ll}\rightarrow & \text { RW } \\ \square- & \text { LESoft }\end{array}$

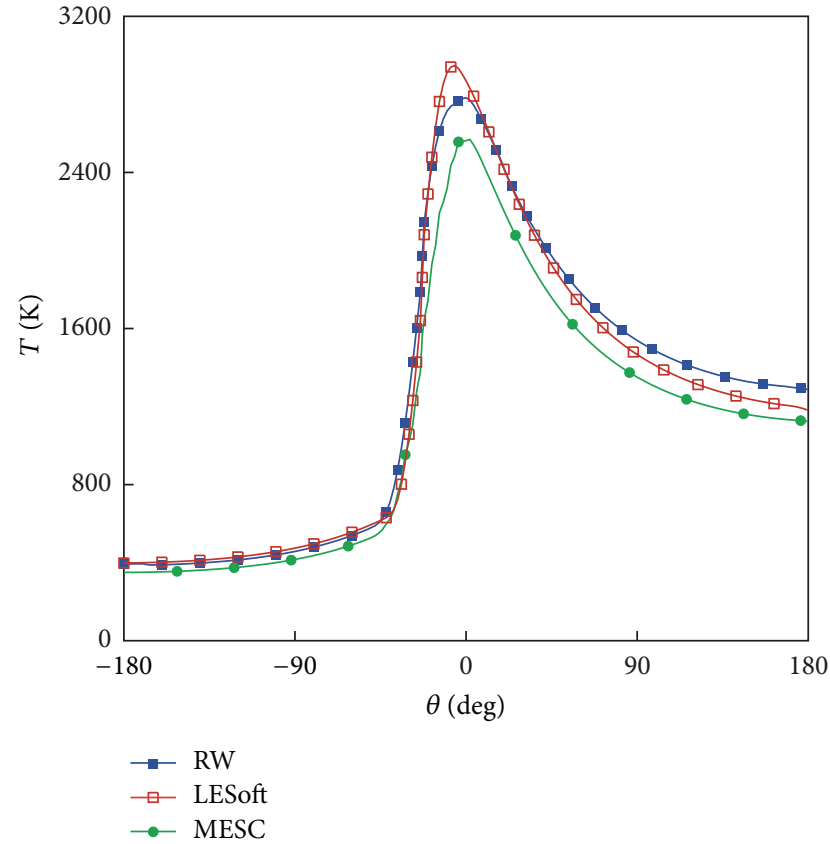

(b)

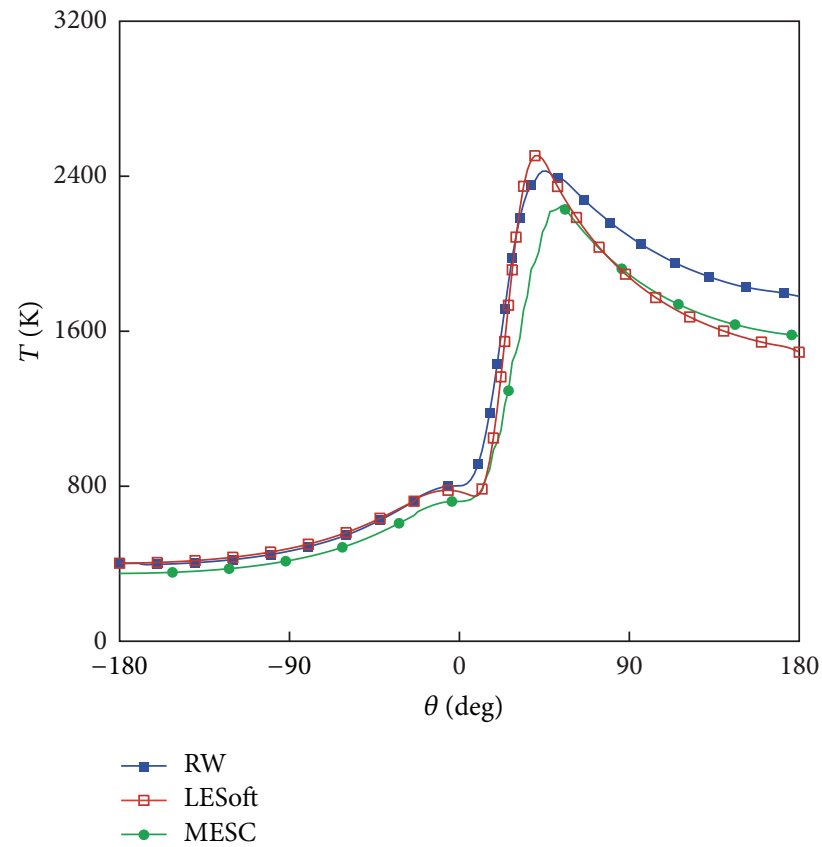

(d)

FIGURE 12: Profiles of temperature for different ignition timing of -60 (a), -50 (b), -10 (c), and 0 (d) degrees.

the corresponding crank angle. Those differences are caused by different assumptions on energy transfer in intake manifold and intake and exhaust valves.

The main discrepancy of the distributions of temperature, predicted with various packages, is related to the location of peak of temperature. These results are shown in Table 7. The temperature profiles before crank angle corresponding to the ignition are very similar. The location of peak of temperature, predicted with LESoft and MESC, takes place earlier than peak of temperature, predicted with RW. The sharp temperature decreasing taking place after the maximum of temperature during the expansion stroke is also similar between LESoft and MESC calculations. RW gives more slowly temperature decreasing during the expansion stroke. 


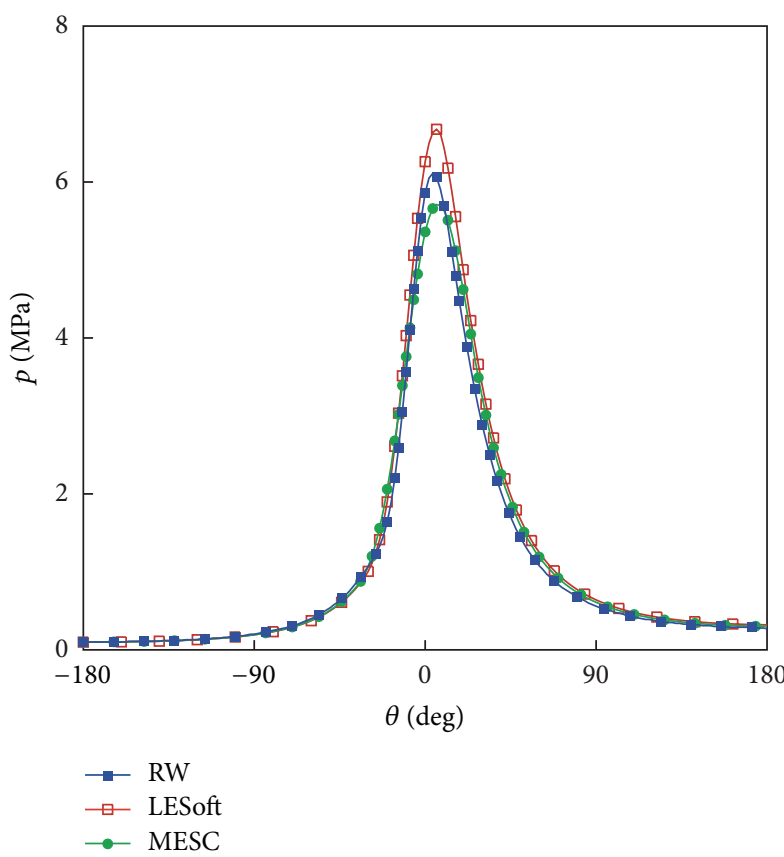

(a)

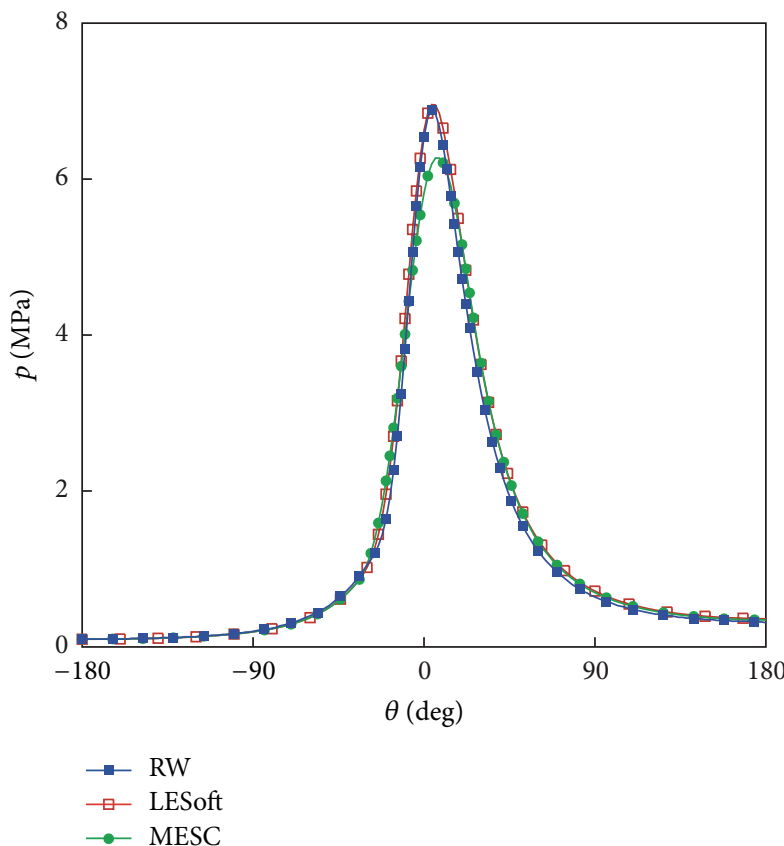

(c)

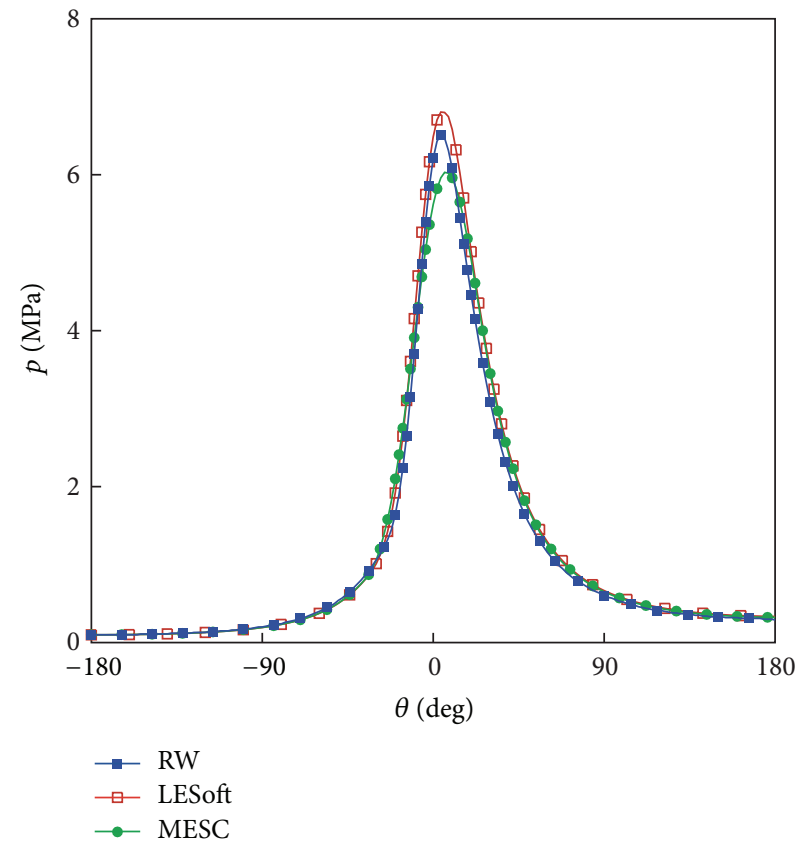

(b)

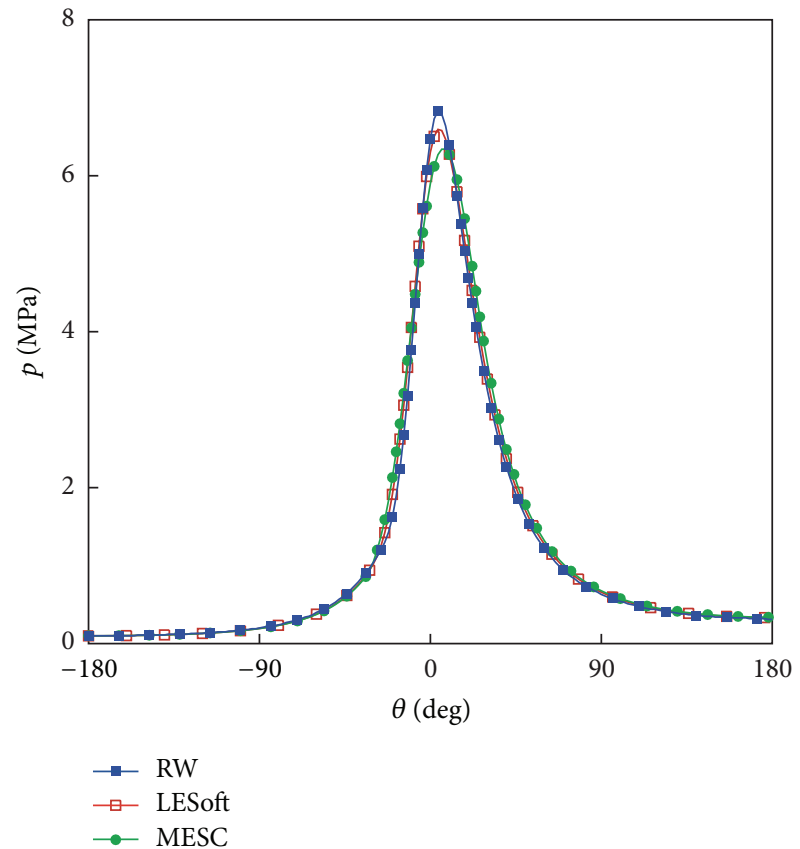

(d)

FIgURE 13: Profiles of pressure for air to fuel ratio of 0.8 (a), 0.9 (b), 1.0 (c), and 1.1 (d).

This behaviour may be explained by the combustion submodel implemented in various packages. In the combustion model, implemented in RW, the timing is determined by the moment of $50 \%$ burned, rather than the start of ignition. The curve of mass fraction burned in LESoft and MESC packages may not be the same as in RW simulation. There is a more rapid increase in temperature when ignition started, until the maximum of temperature reached. This result leads to a higher temperature when combustion finished even though the duration of burn is the same.

The results presented show that if the start of heat release begins too late, it occurs in an expending volume, resulting in lower combustion pressure and lower network. If the start of heat release begins too early during the compression stroke, 


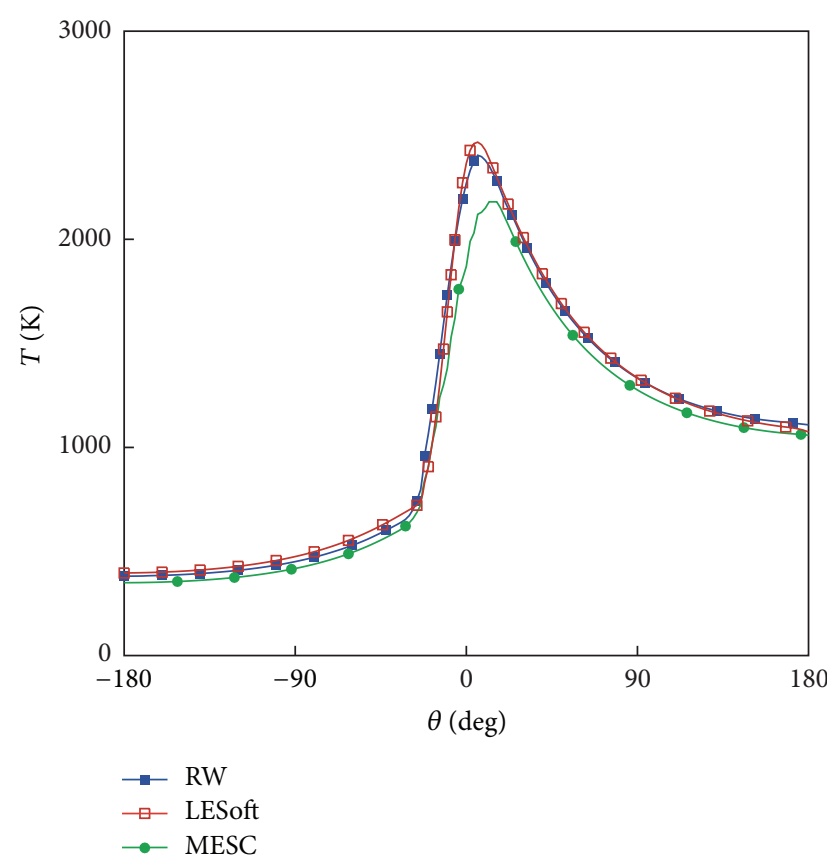

(a)

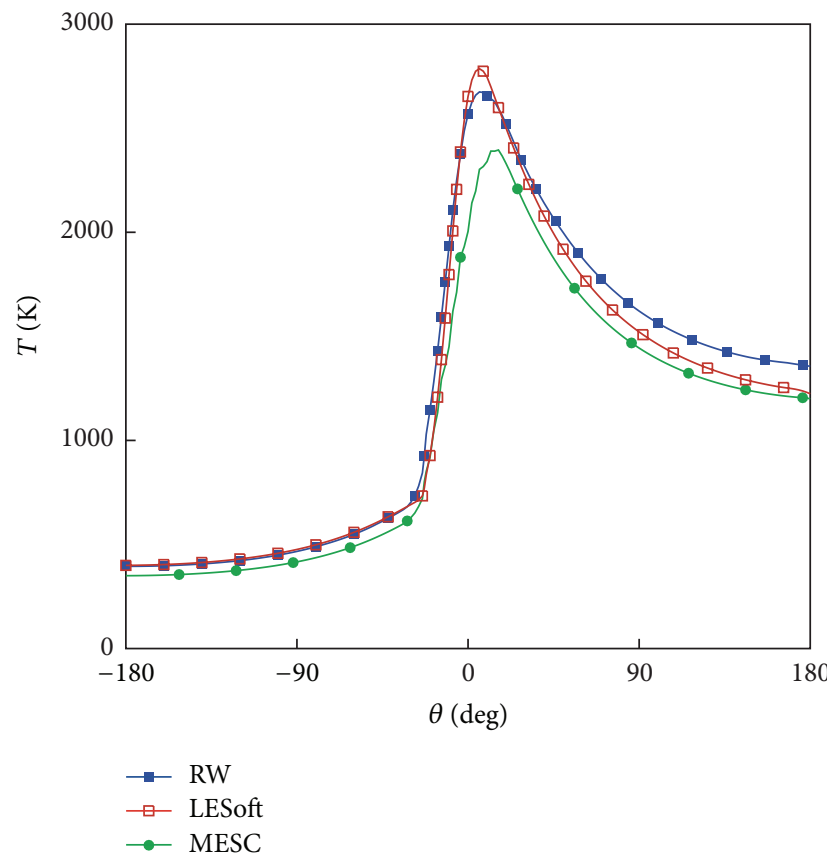

(c)

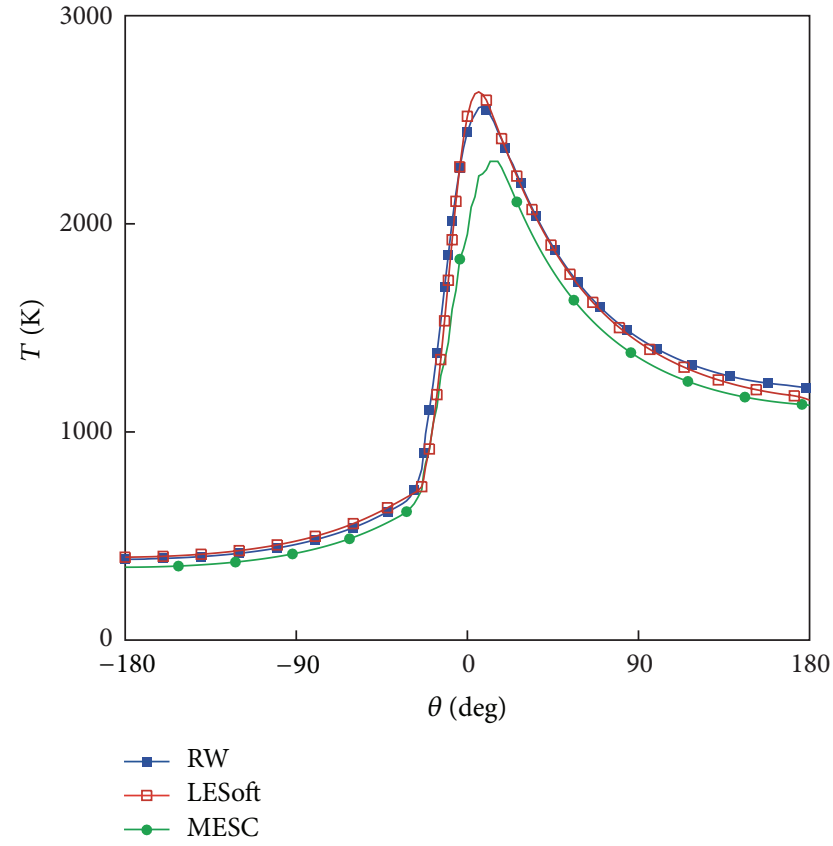

(b)

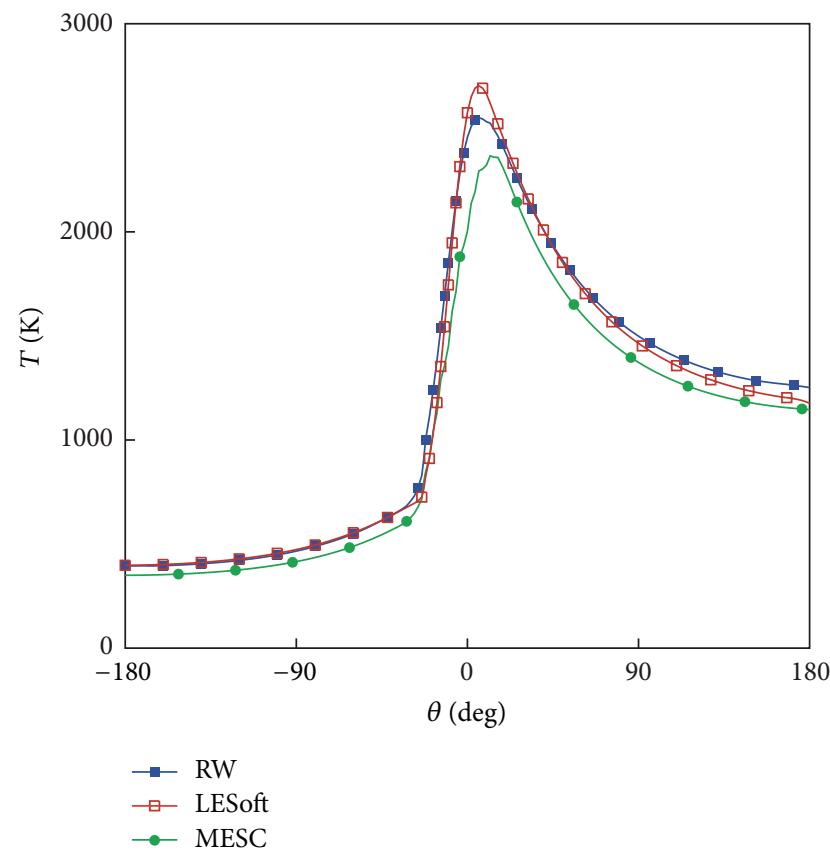

(d)

Figure 14: Profiles of temperature for air to fuel ratios of 0.8 (a), 0.9 (b), 1.0 (c), and 1.1 (d).

the negative compression work increases, since the piston is doing work against the expanding combustion gases. Delay of the initiation of combustion leads to the pressure peak occurring later during the expansion stroke. The pressure rise at $\theta_{s}=-10^{\circ}$ is almost double that at $\theta_{s}=10^{\circ}$. As the start of heat release is changed from $\theta_{s}=-10^{\circ}$ to $\theta_{s}=10^{\circ}$, the work input and the mean effective pressure decrease.
4.5. Varying Air to Fuel Ratio. The profiles of pressure, computed with various packages, are presented in Figure 13 for different air to fuel ratios. All packages predict the maximum pressure level when the air to fuel ratio is stoichiometric. For leaner mixture, RW results are closer to those predicted with LESoft, whereas RW results for richer mixture are closer to the data computed with MESC. The comparison of the 


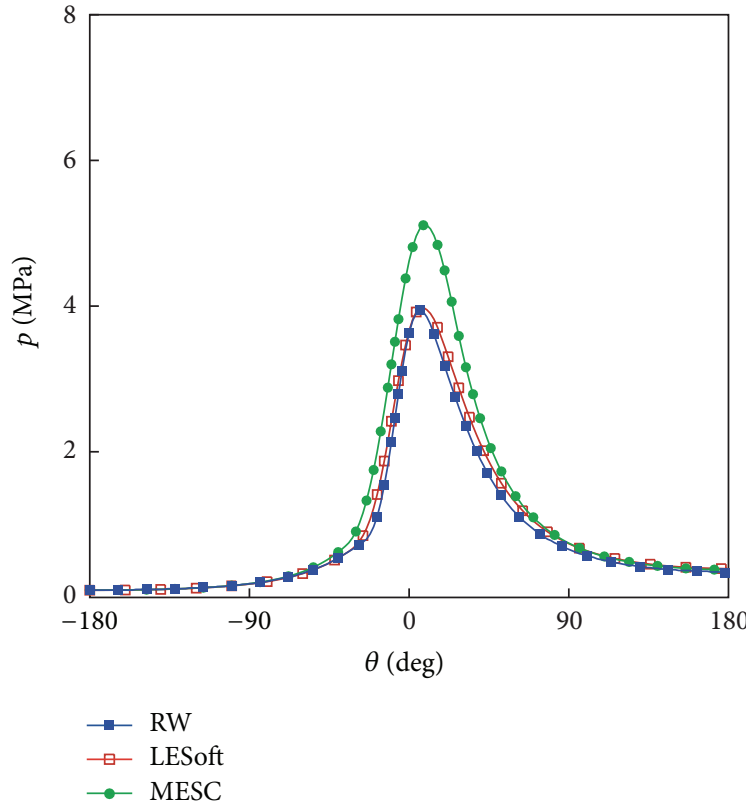

(a)

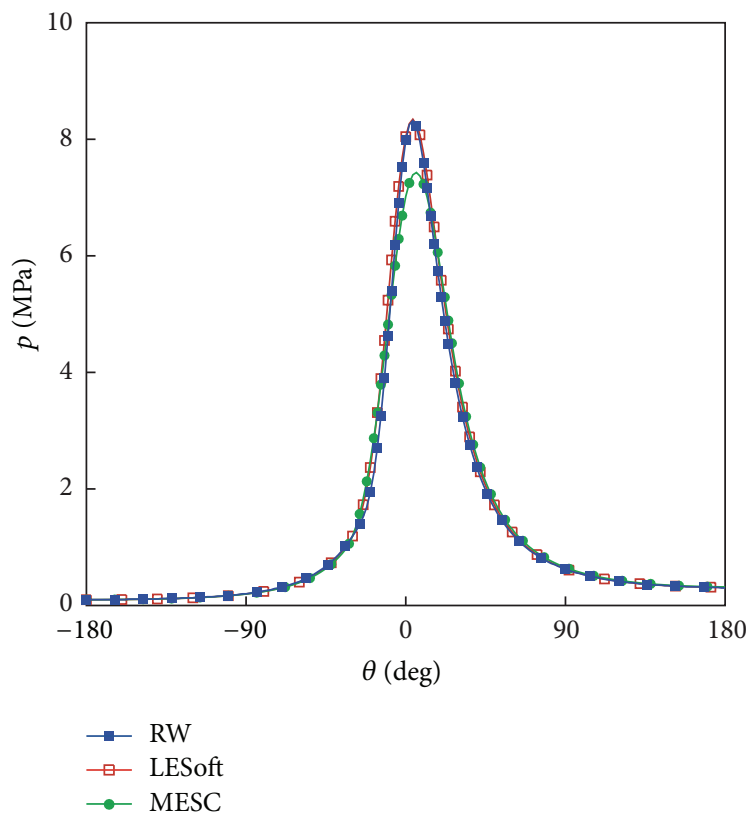

(c)

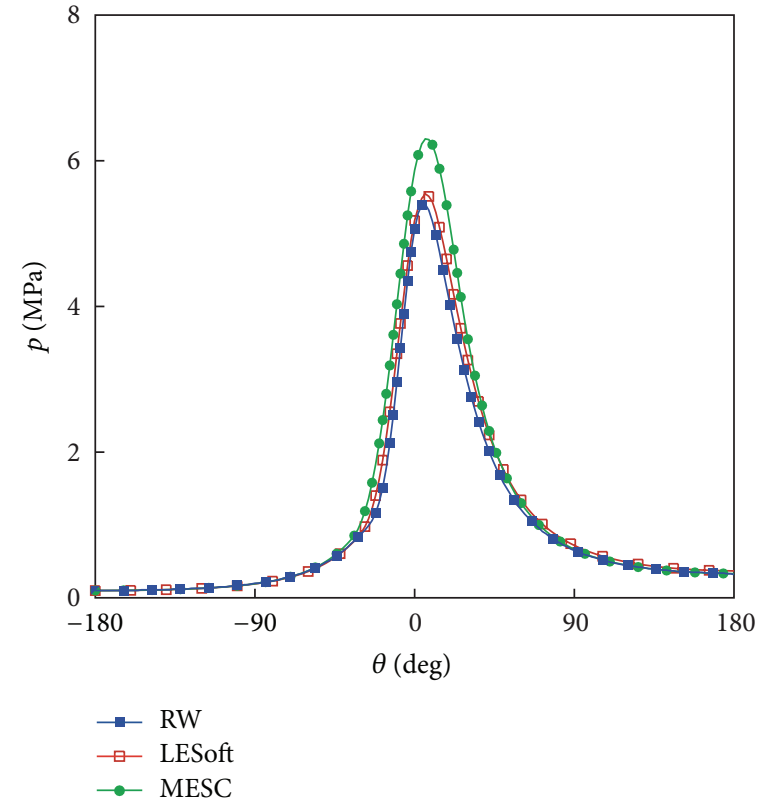

(b)

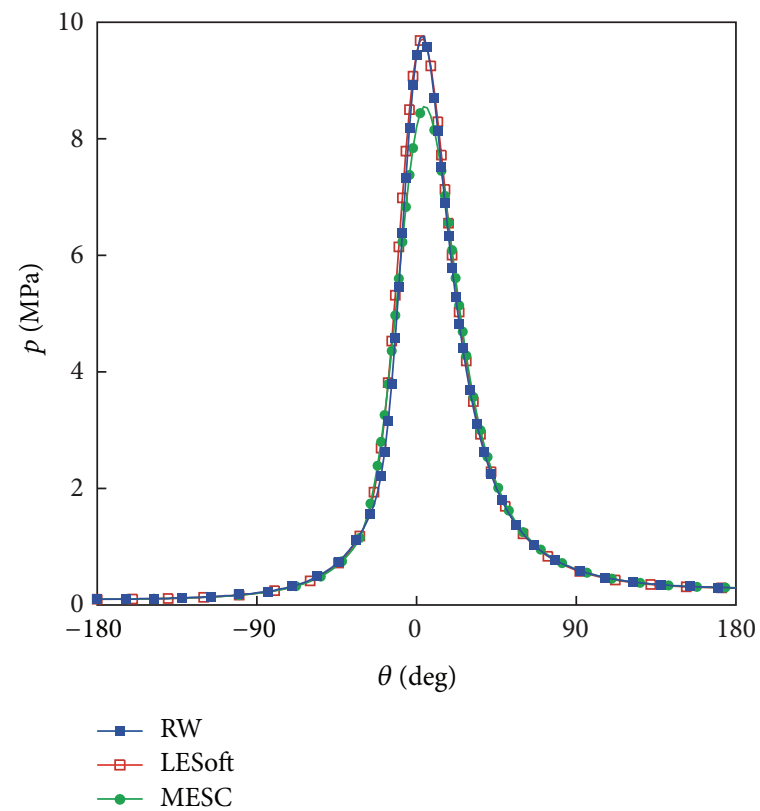

(d)

FIGURE 15: Profiles of pressure for compression ratios of 6 (a), 8 (b), 12 (c), and 14 (d).

pressure profiles show that the shape of profiles is very similar for various packages, but the maximum pressure level is slightly different. The location of pressure peak takes place at the same crank angle for various packages.

The impact of air to fuel ratio on temperature profiles is similar to pressure as this is presented in Figure 14. The maximum temperature occurs when the air to fuel ratio is stoichiometric. RW results are closer to LESoft results for learner mixture and closer to those predicted with MESC for richer mixture. In leaner mixture, RW predicts the location of temperature peak closer to the ignition point compared to MESC results. This may be because RW considers the position of the injection in a pipe, which affects the flow of mixture, and hence takes into account this effect in pressure and temperature distributions computed in the engine cylinder.

4.6. Varying Compression Ratio. Compression ratio is defined as the ratio of the maximum cylinder volume to the minimum volume. The compression ratio determines 


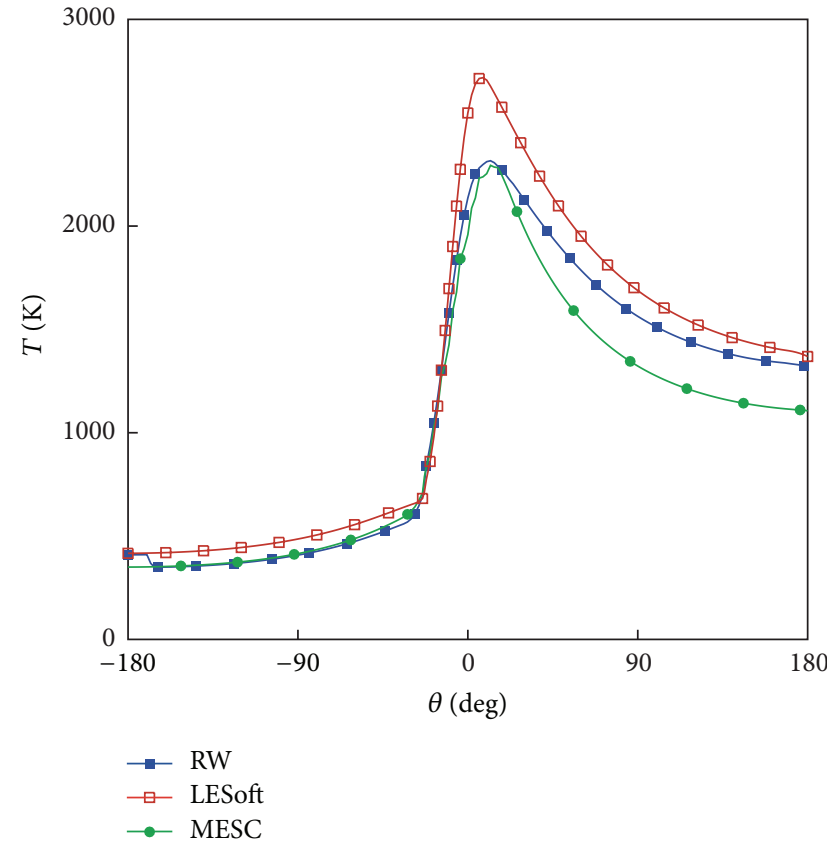

(a)

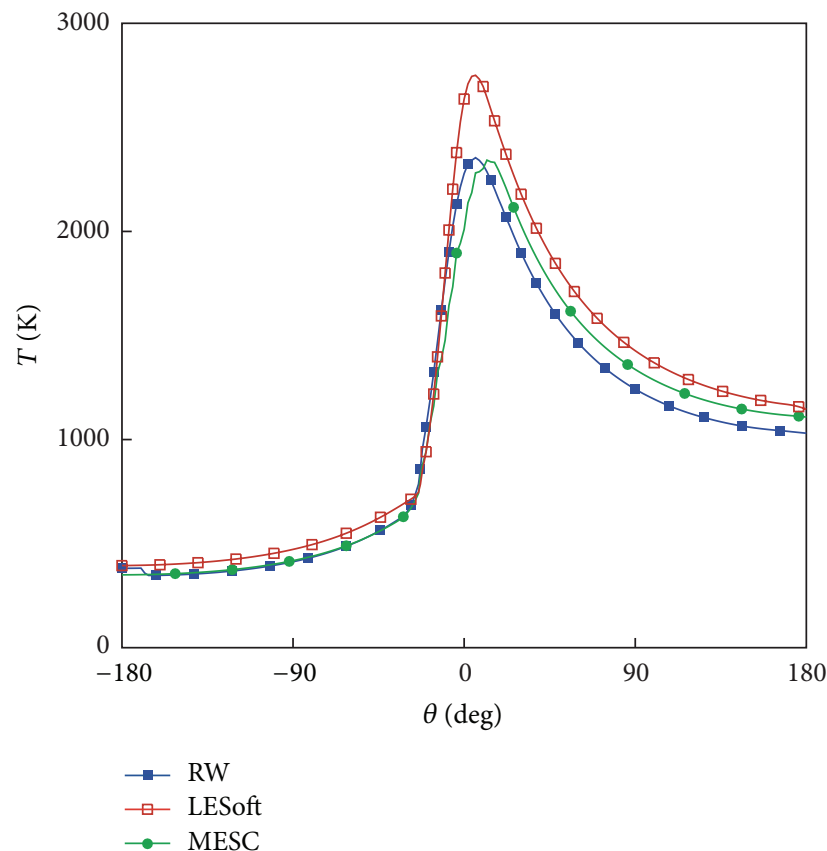

(c)

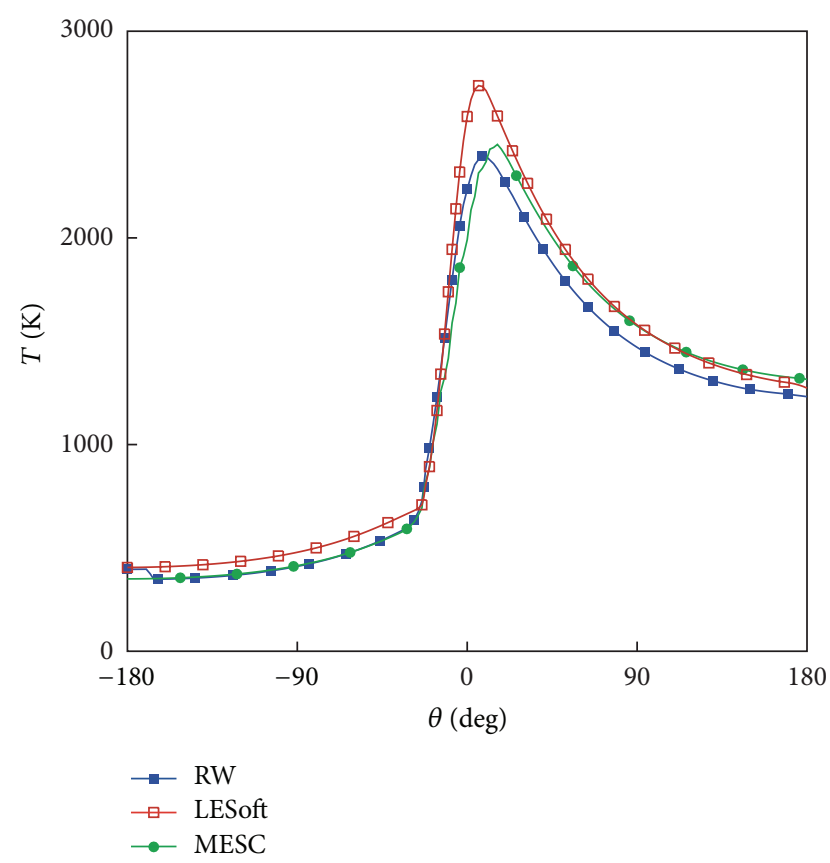

(b)

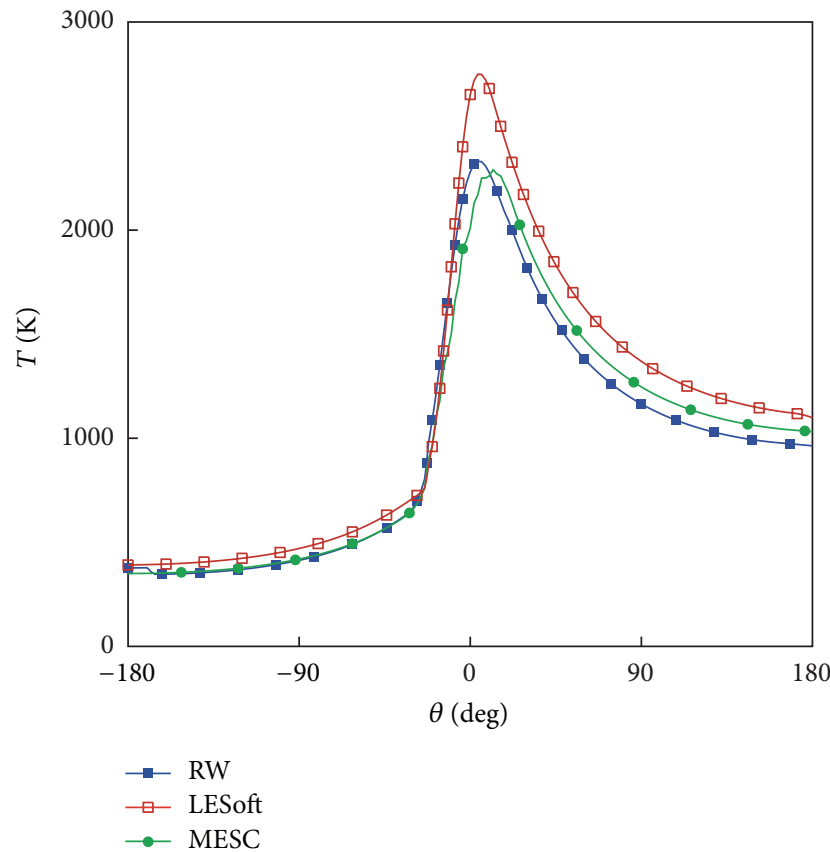

(d)

Figure 16: Profiles of temperature for compression ratios of 6 (a), 8 (b), 12 (c), and 14 (d).

the peak pressure and the peak temperature in the cycle. The efficiency of the engine and formation of pollutants are strong functions of the compression ratio. The compression ratio is limited by the material strength and engine knock. Engine heads and blocks have a design of a maximum stress, which should not be exceeded, limiting the compression ratio. Compression ratio is difficult to control due to fixed geometry of cylinder. In practice, compression ratio can be varied by changing the piston head surface shape.

The results, computed with three packages, are presented in Figure 15. The pressure increases as compression ratio increases, and the data obtained are in agreement with theory $[22,23]$. The position of maximum level of pressure slightly depends on the compression ratio. 
TABLE 6: Location of pressure peak predicted with various packages.

\begin{tabular}{lccc}
\hline $\begin{array}{l}\text { Start of ignition, } \\
\text { deg }\end{array}$ & RW & MESC & LESoft \\
\hline-60 & -2 & -2 & -4 \\
-50 & 2 & 0 & -6 \\
-40 & 2 & 6 & 2 \\
-30 & 8 & 10 & 8 \\
-20 & 14 & 14 & 16 \\
-10 & 22 & 20 & 24 \\
0 & 32 & 30 & 34 \\
\hline
\end{tabular}

TABLE 7: Location of temperature peak predicted with various packages.

\begin{tabular}{lcccc}
\hline $\begin{array}{l}\text { Start of ignition, } \\
\text { deg }\end{array}$ & $\begin{array}{c}\text { RW } \\
\text { burned }\end{array}$ & $\begin{array}{c}\text { RW } \\
\text { averaged }\end{array}$ & $\begin{array}{c}\text { MESC } \\
\text { burned }\end{array}$ & LESoft \\
\hline 60 & -8 & -8 & -16 & -16 \\
-50 & -2 & 0 & -12 & -6 \\
-40 & -6 & 2 & -8 & 2 \\
-30 & 0 & 12 & -4 & 10 \\
-20 & 12 & 24 & 2 & 20 \\
-10 & 22 & 34 & 10 & 30 \\
0 & 28 & 46 & 20 & 40 \\
\hline
\end{tabular}

In LESoft and MESC calculations, the temperature slightly increases as the compression ratio increases as this is presented in Figure 16. In RW calculations, the highest temperature is observed at the compression ratio of 10 .

\section{Conclusions and Recommendations}

Two commercial engine simulation packages, Ricardo Wave and Lotus Engine Simulation, and in-house package, implemented with Matlab, have been considered, and their capabilities to the simulation of compression, expansion, and combustion processes in one-cylinder engine have been compared and discussed. The engine geometry is fixed in the tests performed. The main submodels affecting the results computed are Woschni heat transfer model and Wiebe heat release model.

One-cylinder engine model has been designed with the mentioned packages, and similar engine operating parameters have been specified (where it was possible). The results, computed with three packages, have been compared with reference data. The results obtained for reference test show that RW, LESoft, and MESC predict similar profiles of pressure and temperature which are in reasonable agreement with reference results. In the combustion period, there is a slight shift of location of pressure peak with respect to the location of pressure peak predicted with MESC compared to two commercial packages. Both commercial packages take into account position of fuel injectors, inlet pipes, and valve models which affect air flow and heat transfer in the cylinder.

Engine operating conditions, such as various ignition timings, various air to fuel ratios, and various compression ratios have been considered in the tests, and the results obtained have been discussed. The results, computed with various packages, are in a good agreement. Small discrepancies may be explained by the various implementations of different submodels (heat transfer sub-model and combustion sub-model) and different physical and chemical properties of fuel and combustion products.

By considering the engine control in real driving condition, the in-house engine simulation package is the only one that allows running simulations with changing speed and other operating parameters throughout a simulation period that is required. The code can be used for real-time control purpose using exhaust gas composition of 10 spices.

Future work will focus on comparison of the results computed with real engine bed tests, implementation of the control algorithms of valve timing, ignition timing, and injection timing to control the performance of engine. ECU is capable to update the needed parameters while engines run with alternated fuel compositions.

\section{List of Notations}

$\begin{array}{ll}\text { C: } & \text { Carbon } \\ \text { CFD: } & \text { Computation Fluid Dynamics } \\ \text { CO: } & \text { Carbon oxide } \\ \text { ECU: } & \text { Engine control unit } \\ \text { EGR: } & \text { Exhaust gas recirculation } \\ \text { H: } & \text { Hydrogen } \\ \text { HC: } & \text { Hydrocarbon } \\ \text { ICE: } & \text { Internal Combustion Engine } \\ \text { LESoft: } & \text { Lotus Engine Simulation } \\ \text { LIVC: } & \text { Late intake valve closing } \\ \text { MESC: } & \text { Matlab Engine Simulation Code } \\ \text { N: } & \text { Nitrogen } \\ \text { NOx: } & \text { Nitrogen oxide } \\ \text { O: } & \text { Oxygen } \\ \text { RW: } & \text { Ricardo Wave } \\ \text { SI: } & \text { Spark ignition } \\ \text { TDC: } & \text { Top Dead Centre } \\ \text { VVT: } & \text { Variable valve timing. }\end{array}$

\section{References}

[1] V. A. W. Hillier, Hillier's Fundaments of Automotive Electronics, Nelson, 2nd edition.

[2] Lotus Engineering Software user menu, Lotus Group plc, 2011.

[3] Ricardo software: WAVE user's manual. Version 8.0. Ricardo Inc, 2009.

[4] S. Barclay, "Lotus omnivore engine-10\% better fuel economy than current leading gasoline engines," Automotive Industries AI, vol. 189, no. 12, 2009.

[5] D. W. Blundell, J. Turner, R. Pearson, R. Patel, and J. Young, "The Omnivore wide-range auto-ignition engine: results to date using 98RON unleaded gasoline and E85 Fuels," SAE Paper 2010-01-0846, 2010.

[6] M. A. Ceviz and M. Akin, "Design of a new SI engine intake manifold with variable length plenum," Energy Conversion and Management, vol. 51, no. 11, pp. 2239-2244, 2010. 
[7] M. A. Ceviz, "Intake plenum volume and its influence on the engine performance, cyclic variability and emissions," Energy Conversion and Management, vol. 48, no. 3, pp. 961-966, 2007.

[8] B. Walter, P. Pacaud, and B. Gatellier, "Variable valve actuation systems for homogeneous diesel combustion: how interesting are they?" Oil and Gas Science and Technology, vol. 63, no. 4, pp. 517-534, 2008.

[9] M. Ghazikhani, M. E. Feyz, and A. Joharchi, "Experimental investigation of the Exhaust Gas Recirculation effects on irreversibility and Brake Specific Fuel Consumption of indirect injection diesel engines," Applied Thermal Engineering, vol. 30, no. 11-12, pp. 1711-1718, 2010.

[10] A. Ibrahim and S. Bari, "An experimental investigation on the use of EGR in a supercharged natural gas SI engine," Fuel, vol. 89, no. 7, pp. 1721-1730, 2010.

[11] S. Verhelst, J. Demuynck, R. Sierens, and P. Huyskens, "Impact of variable valve timing on power, emissions and backfire of a bi-fuel hydrogen/gasoline engine," International Journal of Hydrogen Energy, vol. 35, no. 9, pp. 4399-4408, 2010.

[12] E. Mancaruso and B. M. Vaglieco, "Optical investigation of the combustion behaviour inside the engine operating in HCCI mode and using alternative diesel fuel," Experimental Thermal and Fluid Science, vol. 34, no. 3, pp. 346-351, 2010.

[13] A. Gibson and I. Kolmanovsky, "Modeling positive intake valve overlap air charge response in camless engines," in Proceedings of the American Control Conference, pp. 755-760, Denver, Colo, USA, June 2003.

[14] J. Misztal, H. M. Xu, M. L. Wyszynski, P. Price, R. Stone, and J. Qiao, "Effect of injection timing on gasoline homogeneous charge compression ignition particulate emissions," International Journal of Engine Research, vol. 10, no. 6, pp. 419-430, 2009.

[15] T. Urushihara, K. Hiraya, A. Kakuhou, and T. Itoh, "Expansion of HCCI operating region by the combination of direct fuel injection, negative valve overlap and internal fuel reforming," SAE Paper 2003-01-0749, 2003.

[16] Y. Murata, J. Kusaka, M. Odaka et al., "Emissions suppression mechanism of premixed diesel combustion with variable valve timing," International Journal of Engine Research, vol. 8, no. 5, pp. 415-428, 2007.

[17] Z. Peng and M. Jia, "Full engine cycle CFD investigation of effects of variable intake valve closing on diesel PCCI combustion and emissions," Energy and Fuels, vol. 23, no. 12, pp. 5855-5864, 2009.

[18] M. Ishida, S. Yamamoto, H. Ueki, and D. Sakaguchi, "Remarkable improvement of $\mathrm{NO}_{x}$-PM trade-off in a diesel engine by means of bioethanol and EGR," Energy, vol. 35, no. 12, pp. 45724581, 2010.

[19] I. R. Abenavoli, V. Naso, T. Rychter, and A. Teodorczyk, "First experimental analysis of an internal combustion engine with variable stroke and compression ratio," in Proceedings of the 25th Intersociety Energy Conversion Engineering Conference, vol. 2, pp. 198-203, Reno, Nev, USA, August 1990.

[20] J. W. G. Turner, D. W. Blundell, R. J. Pearson et al., "Project omnivore: a variable compression ratio atac 2-stroke engine for Ultra-wide-range HCCI operation on a variety of fuels," $S A E$ International Journal of Engines, vol. 3, no. 1, pp. 938-955, 2010.

[21] D. W. Blundell, J. Turner, R. Pearson, R. Patel, and J. Young, "The Omnivore wide-range auto-ignition engine: results to date using 98RON unleaded gasoline and E85 Fuels," SAE Paper 2010-01-0846, 2010.
[22] J. B. Heywood, Internal Combustion Engine Fundamentals, McGraw-Hill, New York, NY, USA, 1988.

[23] C. R. Ferguson and A. T. Kirkpatrick, Internal Combustion Engines: Applied Thermosciences, John Wiley and Sons, New York, NY, USA, 2001. 

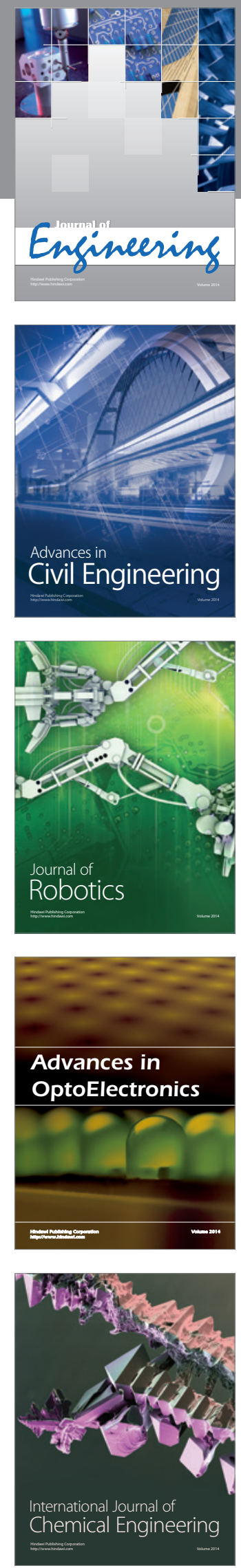

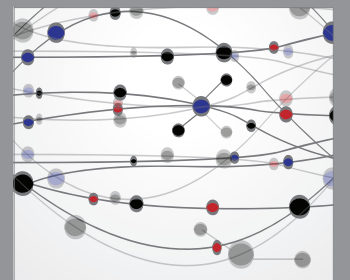

The Scientific World Journal
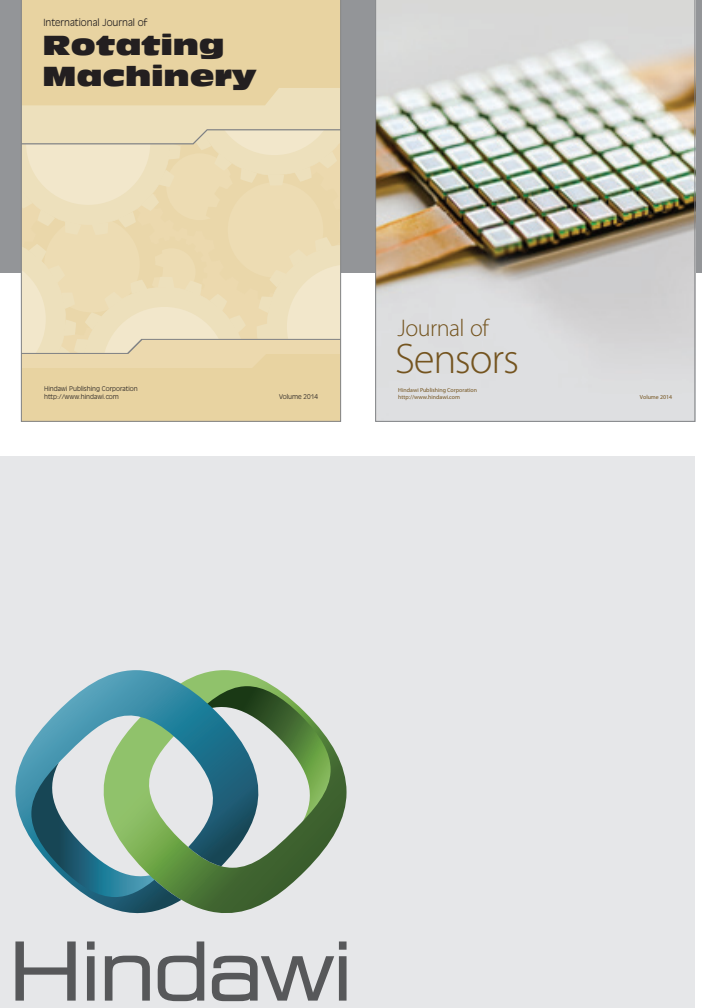

Submit your manuscripts at http://www.hindawi.com
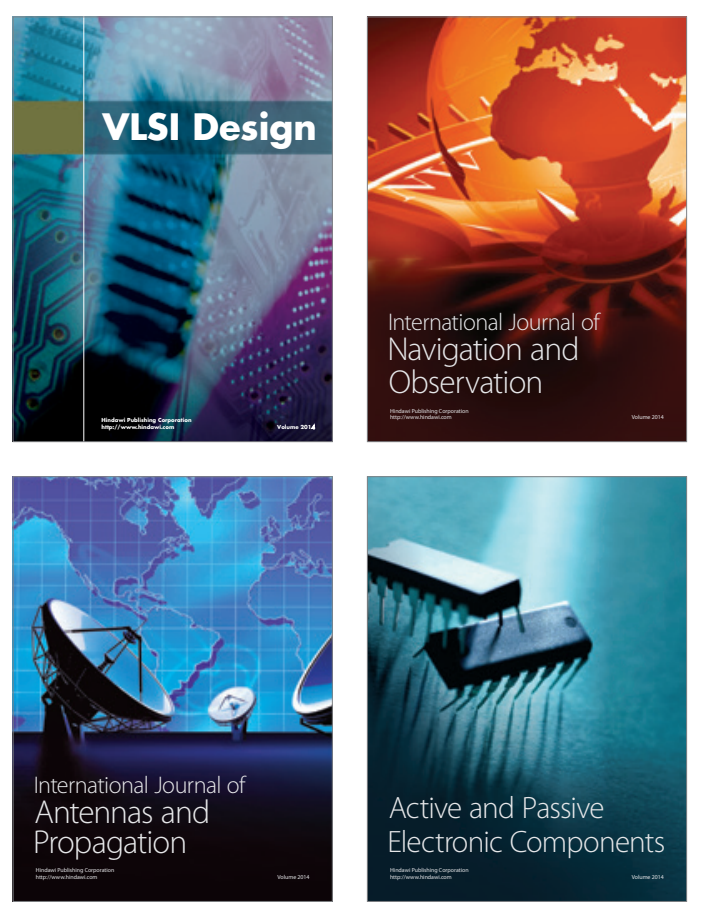
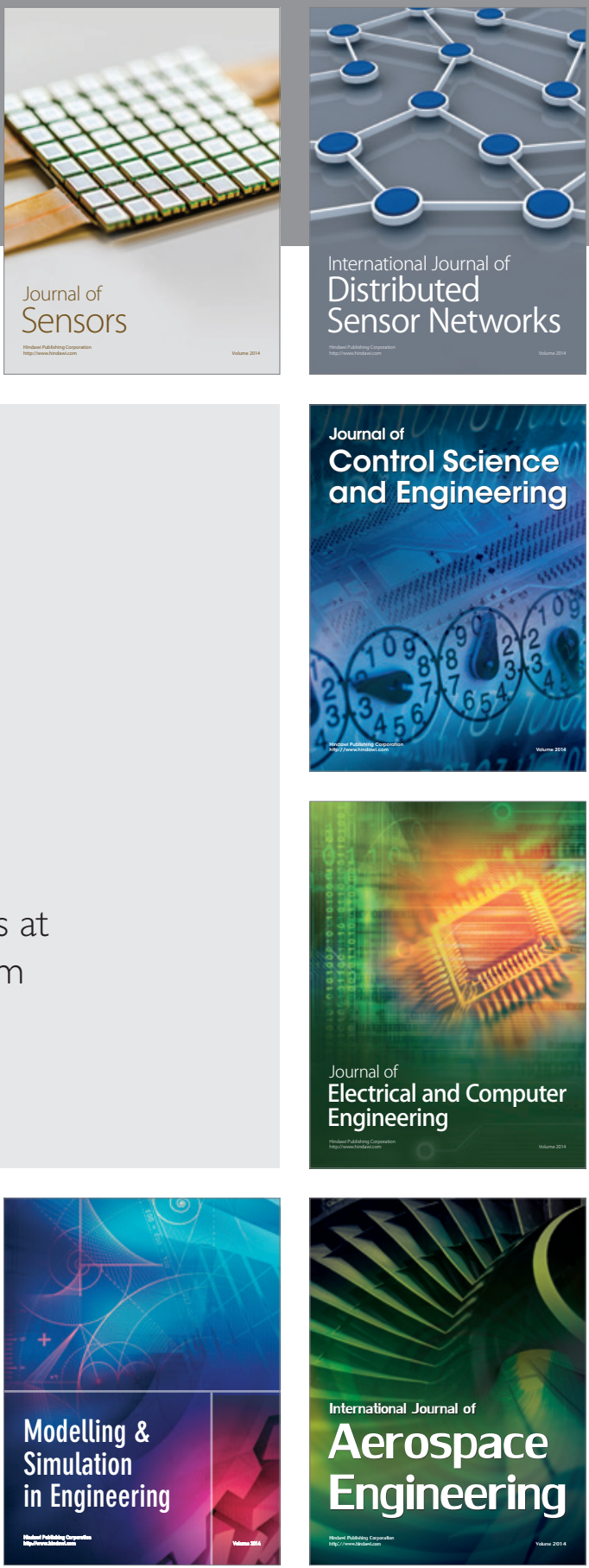

Journal of

Control Science

and Engineering
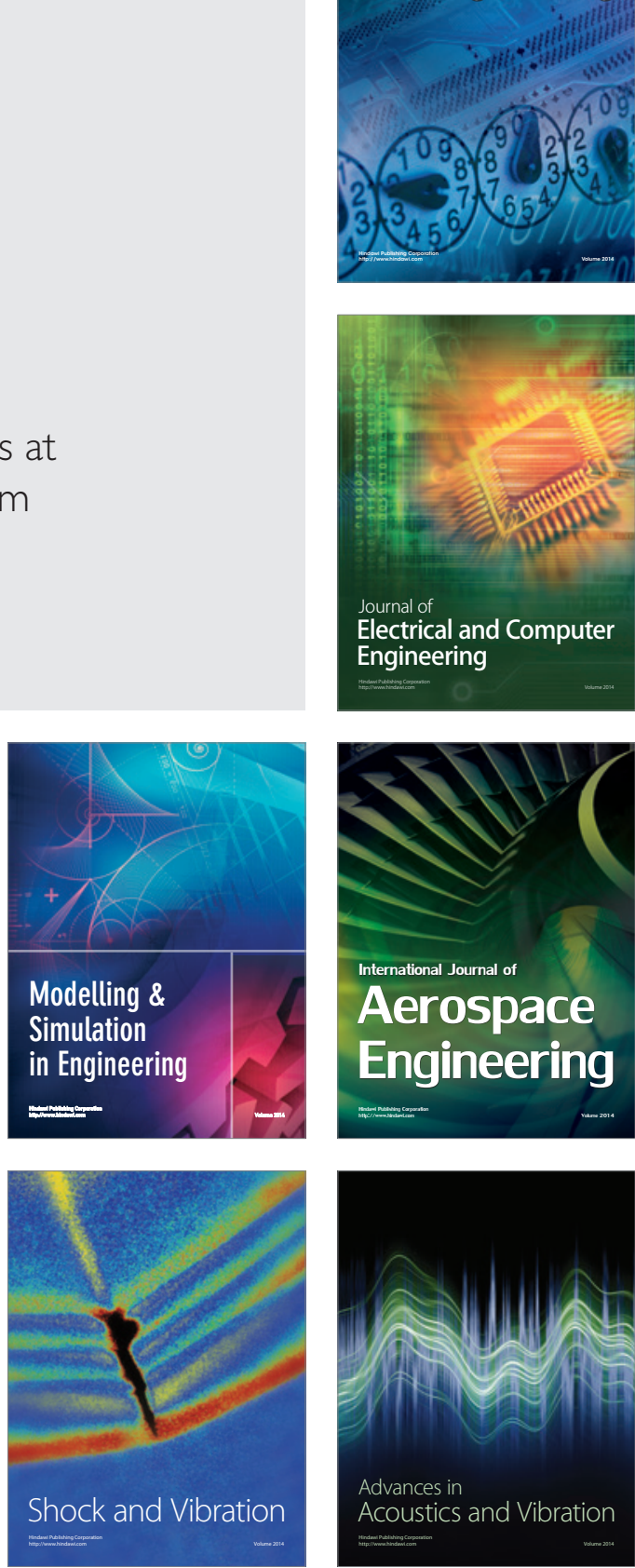